\title{
GASES DE NITROGÊNIO REATIVO COMO PRECURSORES DO AEROSSOL ATMOSFÉRICO: REAÇÕES DE FORMAÇÃO, PROCESSOS DE CRESCIMENTO E IMPLICAÇÕES AMBIENTAIS
}

\author{
Carolina G. Rocha ${ }^{\mathrm{a}}$ e Arnaldo A. Cardoso ${ }^{\mathrm{a}, *,(\mathbb{D}}$ \\ aDepartamento de Química Analítica, Físico-Química e Inorgânica, Instituto de Química, Universidade Estadual Paulista, $14800-060$ \\ Araraquara - SP, Brasil
}

Recebido em 22/09/2020; aceito em 10/11/2020; publicado na web em 11/12/2020

\begin{abstract}
REACTIVE NITROGEN GASES AS PRECURSORS OF ATMOSPHERIC AEROSOL: FORMATION REACTIONS, GROWTH PROCESSES AND ENVIRONMENTAL IMPLICATIONS. The increased emissions of reactive nitrogen gases from anthropogenic sources to the atmosphere has been pointed out as responsible for triggering a series of environmental problems at the local, regional, and global scale. Among the many consequences associated with the excess of reactive nitrogen in the environment is the increase of atmospheric aerosol formation. In this way, the present review article aims to provide an overview of the main aerosol formation reactions from the reactive nitrogen gases, their growth processes, and removal from the atmosphere. The paper also addresses the implications of increasing the atmospheric aerosol load, including effects on the planet's radiative forcing, cloud formation and precipitation, macronutrient dispersion, visibility and human health. The possible relationship between the long-term exposure to these pollutants and COVID-19 fatality is also discussed. The need for more information related to reactive nitrogen gases and atmospheric aerosols is urgent since they act on fundamental processes on planet Earth and their quantity and composition have been abruptly changed over the last hundred years. Therefore, further investigations on this topic should be stimulated and better integrated in order to guide normative decisions and the delineation of possible solutions.
\end{abstract}

Keywords: reactive nitrogen; atmospheric aerosol; nitrogen deposition.

\section{INTRODUÇÃO}

O ano de 2020 foi marcado pela agressiva pandemia de COVID-19. A doença, provocada por um novo coronavírus (SARSCoV-2) inicialmente identificado em Wuhan na China, rapidamente se disseminou ao redor do mundo provocando um surto global que contabilizou milhões de infectados e milhares de mortes somente no primeiro semestre do ano de 2020. ${ }^{1}$ Medidas adotadas para contenção da propagação do vírus fizeram com que parte da população das grandes cidades do planeta reduzissem suas atividades ao mínimo. Nesse contexto, foi destaque a forte redução na poluição atmosférica associada ao gás $\mathrm{NO}_{2}$ no entorno de áreas urbanas e a consequente redução de mortes provocadas pela poluição atmosférica. ${ }^{2-4} \mathrm{Em}$ contrapartida, correlações entre o aumento nas taxas de mortalidade causada pela COVID-19 e a concentração de poluentes atmosféricos, particularmente material particulado fino, vem sendo demonstrada. ${ }^{5,6}$ Esses fatos evidenciam a importância dos compostos de nitrogênio para a poluição no século XXI.

$\mathrm{O}$ nitrogênio (N) é um elemento químico indispensável para a existência da vida. Ele constitui uma parte importante dos ácidos nucléicos, que determinam o caráter genético de todos os organismos vivos e está presente nas proteínas enzimáticas, que são responsáveis pelo maquinário metabólico de toda célula viva; ${ }^{7}$ é também um dos macronutrientes essenciais para o crescimento vegetal, cuja capacidade fotossintética está diretamente relacionada à disponibilidade desse elemento. ${ }^{8}$

Apesar de abundante - aproximadamente $4 \times 10^{21} \mathrm{~g}$ de nitrogênio estão distribuídos no solo, água e atmosfera da Terra - o nitrogênio é encontrado na natureza majoritariamente em sua forma quimicamente inerte e biologicamente pouco assimilável pelos seres vivos, o gás $\mathrm{N}_{2} \cdot{ }^{9}{ }^{10}$ A quebra da tripla ligação que une os dois átomos de nitrogênio requer uma energia notavelmente elevada $\left(225 \mathrm{kcal} \mathrm{mol}^{-1}\right)$, o que faz

*e-mail: arnaldo.cardoso@unesp.br com que o gás $\mathrm{N}_{2}$ seja bastante estável e, por consequência, pouco reativo. ${ }^{11,12}$

Antes que o nitrogênio possa ser utilizado pela maior parte das plantas, animais, insetos e microrganismos, as ligações da molécula de $\mathrm{N}_{2}$ devem ser primeiramente rompidas, e os átomos de $\mathrm{N}$ resultantes devem estar quimicamente ligados a outros elementos, tais como, oxigênio e/ou hidrogênio e carbono. ${ }^{10} \mathrm{Na}$ natureza, somente processos envolvendo altas temperaturas, tais como ocorrem durante descargas elétricas atmosféricas, ou microrganismos especializados na fixação de nitrogênio, são capazes de efetuar essa quebra. ${ }^{13} \mathrm{O}$ termo "fixação", como empregado neste artigo, denomina o processo de transformação do $\mathrm{N}_{2}$ atmosférico não-reativo em espécies de $\mathrm{N}_{\mathrm{r}}$ assimiláveis pelas plantas e animais.

Assim, em termos de classificação, todos os compostos de nitrogênio biologicamente, fotoquimicamente e radiativamente ativos na atmosfera e biosfera da Terra são designados como compostos de "nitrogênio reativo" $\left(\mathrm{N}_{\mathrm{r}}\right)$, e incluem as formas reduzidas $\left(\mathrm{NH}_{3}\right.$ e $\mathrm{NH}_{4}^{+}$), oxidadas ( $\mathrm{NO}, \mathrm{NO}_{2}, \mathrm{HNO}_{3}, \mathrm{~N}_{2} \mathrm{O}$ e $\mathrm{NO}_{3}^{-}$) e os compostos orgânicos nitrogenados (ureia, aminas e proteínas), em contraste com o gás $\mathrm{N}_{2}$ não-reativo. ${ }^{14}$

A disponibilidade limitada de $\mathrm{N}_{\mathrm{r}}$ advindo de processos naturais fez com que os ecossistemas do nosso planeta se tornassem adaptados à pequenas taxas de fornecimento de $\mathrm{N}$, com produtividade restrita, mas elevada diversidade. ${ }^{15}$ A baixa disponibilidade desse nutriente torna-se crítica, entretanto, quando consideramos sistemas agrícolas, os quais visam por característica, a obtenção de alta produtividade. Durante muito tempo a humanidade dedicou-se a buscar fontes de nitrogênio que pudessem ser utilizadas na agricultura e, assim, suprir a necessidade da crescente demanda pela ampliação da oferta de alimentos. Tal necessidade foi especialmente agravada durante o século XIX, período em que a população mundial cresceu rapidamente, com destaque para Europa, que impulsionada pela Revolução Industrial, viu sua população dobrar nesse período. ${ }^{16}$ 
A solução para a busca de nitrogênio em uma forma que de fato pudesse ser aproveitado na agricultura viria somente no início do século XX. Fritz Haber e Carl Bosch descobriram e aprimoraram um processo no qual a amônia, $\mathrm{NH}_{3}$, um composto de nitrogênio reativo, poderia ser sintetizado a partir da reação do nitrogênio atmosférico, $\mathrm{N}_{2}$, com hidrogênio, $\mathrm{H}_{2}$, na presença de ferro a altas pressões e temperaturas, e ser produzida em escala industrial. Esse processo, que ficou conhecido como Processo Haber-Bosch, é considerado um dos principais marcos da química daquele século. ${ }^{17,18}$

Com a consolidação do Processo Haber-Bosch, a produção de fertilizantes sintéticos nitrogenados foi amplamente expandida, permitindo o aumento na produção de alimentos, que foi acompanhado por um acelerado crescimento populacional. ${ }^{19}$ Entre 1901 e 2001, a população mundial saltou de 1,1 bilhão para 6 bilhões de pessoas e, em 2019, a marca de 7,7 bilhões já havia sido ultrapassada. ${ }^{20} \mathrm{~A}$ amônia produzida industrialmente está atualmente disponível em abundância e acessível em todo o mundo desenvolvido. Estima-se que sem o $\mathrm{N}_{\mathrm{r}}$ adicional produzido pelo processo Haber-Bosch, apenas 3 bilhões de pessoas - menos de $50 \%$ da população global atual - teriam comida suficiente, dadas as dietas e práticas agrícolas atuais. ${ }^{21}$

Além do enorme impacto na indústria de fertilizantes e alimentos, a amônia advinda do Processo Haber-Bosch atendeu também a demanda por matéria-prima para produção de explosivos, tornandose essencial para a produção de munições, utilizadas em todos os conflitos armados ocorridos no mundo desde então. A amônia é também utilizada para a produção de uma série de compostos químicos e produtos sintéticos comerciais tais como, produtos de higiene, fibras têxteis, colas, corantes e plásticos. ${ }^{22}$

Além da entrada intencional de $\mathrm{N}_{\mathrm{r}}$ no meio ambiente por meio de sua produção industrial (Processo Haber-Bosch), atividades humanas que dependem de processos de combustão acabam contribuindo de forma não intencional para a entrada de grandes quantidades de $\mathrm{N}_{\mathrm{r}}$ na atmosfera. Os processos de combustão geram energia térmica suficiente para promover reações secundárias entre o nitrogênio $\left(\mathrm{N}_{2}\right)$ e o oxigênio $\left(\mathrm{O}_{2}\right)$, componentes majoritários do ar atmosférico, levando à produção de monóxido de nitrogênio (NO), que por sua vez é rapidamente oxidado a dióxido de nitrogênio $\left(\mathrm{NO}_{2}\right)$, devido à presença de compostos oxidantes na atmosfera, como o ozônio $\left(\mathrm{O}_{3}\right)$, por exemplo. ${ }^{23}$ Assim, o transporte por veículos com motores à combustão, as usinas termoelétricas, as indústrias que utilizam combustíveis em larga escala em seu processo de produção e a queima de biomassa são fontes significativas de gases de $\mathrm{N}_{\mathrm{r}}$ para o meio ambiente.

Nesse contexto, a disponibilidade de alimentos promovida pelos fertilizantes nitrogenados impulsionou o crescimento das cidades, as quais passaram a consumir cada vez mais energia e depender de diversas formas de transporte; como consequência, as cidades passaram a emitir mais óxidos de nitrogênio provenientes do processo de combustão. Atualmente, mais da metade da população do mundo vive em cidades e, segundo estimativas da ONU (Organização das Nações Unidas), cerca de $68 \%$ da população mundial deverá viver em áreas urbanas até 2050. ${ }^{24}$ Esse modelo de urbanismo provoca um forte crescimento nas emissões de compostos de nitrogênio reativo no ambiente e esses, por sua vez, geram um impacto que supera os limites da sustentabilidade do planeta. ${ }^{25} \mathrm{O}$ problema é complexo, pouco discutido fora dos meios acadêmicos e sem perspectivas de solução nesses primeiros vinte anos de século XXI.

$\mathrm{O}$ ciclo do $\mathrm{N}$ seja talvez o mais alterado dentre os principais ciclos biogeoquímicos. ${ }^{26} \mathrm{~A}$ entrada massiva de $\mathrm{N}_{\mathrm{r}}$ de origem antrópica no meio ambiente, ocorrida após a Revolução Industrial e, mais acentuadamente, após o desenvolvimento do Processo Haber-Bosch, impactou o ciclo global do nitrogênio devido à disponibilização excessiva desse material para a atmosfera, solo e corpos d'água, ocasionando uma série de problemas ambientais. $\mathrm{O} \mathrm{N}_{\mathrm{r}}$ tem a capacidade de transitar com facilidade pelos diferentes compartimentos ambientais, e isso se deve às caraterísticas químicas do $\mathrm{N}$, que pode assumir número de oxidação entre $-3 \mathrm{e}+5 \mathrm{e}$, portanto, participar de diferentes classes de reações, formando diferentes compostos. $\mathrm{O}$ aumento da concentração de muitos desses compostos pode afetar significativamente o ambiente em escalas local, regional e global. A sucessão de transformações químicas sofridas pelo $\mathrm{N}_{\mathrm{r}} \mathrm{e}$ os respectivos prejuízos ambientais resultantes são conhecidos como cascata de nitrogênio (Figura 1).

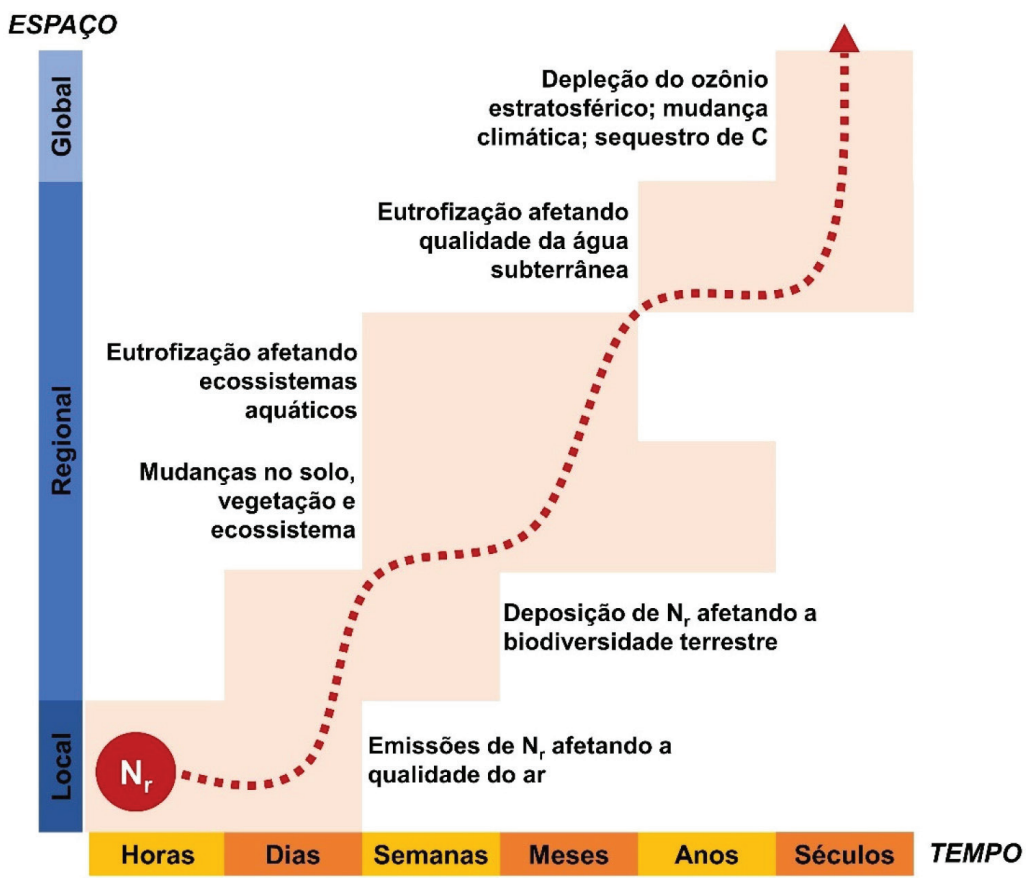

Figura 1. Representação esquemática da cascata de nitrogênio demonstrando como os efeitos de um único átomo de $N_{r}$ se amplificam no tempo e espaço. Adaptado de Erisman $2015^{21}$ e reproduzido com permissão do autor 
Para exemplificar os efeitos da cascata do $\mathrm{N}_{\mathrm{r}}$ no ambiente, podemos considerar um possível histórico de transformações de um átomo de $\mathrm{N}_{\mathrm{r}}$ emitido para a atmosfera a partir da queima de combustível. $\mathrm{O}$ nitrogênio gás não-reativo $\left(\mathrm{N}_{2}\right)$ presente no ar atmosférico é transformado termicamente e na presença de $\mathrm{O}_{2}$ em uma molécula de monóxido de nitrogênio, NO. Uma vez formada, essa molécula é rapidamente oxidada à $\mathrm{NO}_{2}$, pelo ozônio ou outro agente oxidante presente na atmosfera. $\mathrm{Na}$ presença de compostos orgânicos voláteis (COV) e luz solar, a molécula de $\mathrm{NO}_{2}$ pode atuar como fotocatalisador da formação de ozônio troposférico, um poluente gasoso que contribui para diminuição da qualidade do ar. Outra possibilidade de reação entre a molécula de $\mathrm{NO}_{2}$ em presença de produtos de oxidação de $\mathrm{COV}$, é a formação de molécula de PAN (nitrato de peroxiacetila), composto altamente tóxico, capaz de estabilizar a molécula de $\mathrm{NO}_{2}$ e transportá-la para locais distantes da fonte de emissão. Sob diferentes condições ambientais, a molécula de $\mathrm{NO}_{2}$ pode ser regenerada do PAN, e reagir com o radical hidroxila $(\mathrm{OH} \cdot)$ na atmosfera, gerando ácido nítrico $\left(\mathrm{HNO}_{3}\right)$. A amônia $\left(\mathrm{NH}_{3}\right)$, que é um gás básico muito comum encontrado na atmosfera, pode então reagir com o ácido nítrico $\left(\mathrm{HNO}_{3}\right)$ e formar partículas finas na atmosfera, as quais têm efeitos deletérios à saúde humana. Alternativamente, tanto a molécula de $\mathrm{HNO}_{3}$ como sua forma iônica podem retornar ao solo via processos de deposição seca e úmida. No solo, o ácido nítrico reage com espécies básicas inertes, tais como $\mathrm{Al}_{2} \mathrm{O}_{3}$ ou $\mathrm{PbO}$, ocasionando a liberação de espécies tóxicas aos vegetais $\left(\mathrm{Al}^{3+}\right)$, ou ao homem $\left(\mathrm{Pb}^{2+}\right)$. Em uma outra possibilidade, a molécula de $\mathrm{HNO}_{3}$ pode ser depositada em um corpo d'água, onde o $\mathrm{NO}_{3}{ }^{-}$poderá atuar no aceleramento de processo de eutrofização. Tanto no solo como na água, a ação de bactérias naturais pode ainda transformar o nitrato em óxido nitroso, $\mathrm{N}_{2} \mathrm{O}$, um gás de efeito estufa com potencial de aquecimento 296 vezes superior à do $\mathrm{CO}_{2}{ }^{27}$ Esse $\mathrm{N}_{2} \mathrm{O}$ é praticamente inerte na troposfera, mas pode atingir a estratosfera, onde é passível de fotólise levando à formação de $\mathrm{NO}_{\mathrm{x}}$ $\left(\mathrm{NO}_{\mathrm{x}} \equiv \mathrm{NO}+\mathrm{NO}_{2}\right)$, contribuindo para o esgotamento do ozônio estratosférico e para o agravamento da mudança climática. ${ }^{17,21}$ Essa capacidade que um único átomo de $\mathrm{N}_{\mathrm{r}}$ tem de se transformar e formar compostos que atuam em diferentes processos e compartimentos ambientais é única entre os átomos.

Enquanto o $\mathrm{N}_{\mathrm{r}}$ permanece no ambiente, o efeito em cascata continua. Para agravar o problema, é possível ainda que o átomo de $\mathrm{N}_{\mathrm{r}}$ faça o caminho inverso na cascata; por exemplo, a ação de bactérias no solo pode transformar o íon nitrato $\left(\mathrm{NO}_{3}^{-}\right)$em monóxido de nitrogênio novamente. A consequência desse fato é que a fonte original de $\mathrm{N}_{\mathrm{r}}$ não pode ser determinada devido às muitas transformações e interações sofridas pelo átomo de $\mathrm{N}$ nos diferentes processos. ${ }^{28}$

A única maneira de interromper o processo de cascata do $\mathrm{N}_{\mathrm{r}}$ se dá quando em algum momento desse ciclo, o $\mathrm{N}$ é devolvido à atmosfera na forma de nitrogênio não-reativo, $\mathrm{N}_{2}$. Essa transformação é realizada naturalmente por bactérias presentes no solo durante o processo de desnitrificação. ${ }^{29}$

\section{$O$ excesso de $\mathrm{N}_{\mathrm{r}}$ no ambiente}

As atividades antrópicas têm aumentado drasticamente a quantidade de $\mathrm{N}_{\mathrm{r}}$ presente no ambiente. A atividade antrópica dominante nesse quesito é a agricultura, que produz novo $\mathrm{N}_{\mathrm{r}}$ através de cultivos de fixação biológica induzida, e pela aplicação de fertilizantes sintéticos nitrogenados, que utilizam a amônia do Processo HaberBosch como matéria-prima. A queima de combustíveis fósseis para a produção de energia também tem contribuído para o aumento de $\mathrm{N}_{\mathrm{r}}$ no ambiente, uma vez que $\mathrm{NO}_{\mathrm{x}}$ é formado como subproduto no processo de combustão. De igual magnitude global à geração de $\mathrm{N}_{\mathrm{r}}$ advindo da queima de combustíveis fósseis, tem-se ainda a $\mathrm{NH}_{3}$ advinda do Processo Haber-Bosch, que é empregada como matériaprima na produção de uma variedade de outros artigos industriais, como, por exemplo, nylon e explosivos. ${ }^{30}$

Globalmente, cerca de $75 \%$ da produção de $\mathrm{N}_{\mathrm{r}}$ antrópico é resultante da fixação industrial de N (Processo Haber-Bosch) e 25\% da queima de combustíveis fósseis e biomassa (na forma de óxidos de nitrogênio). A produção total de $\mathrm{N}_{\mathrm{r}}$ devido à agricultura é hoje mais do que o dobro da quantidade pré-industrial naturalmente produzida nos ecossistemas terrestres..$^{21}$ Atualmente, as atividades humanas estão dominando a introdução de $\mathrm{N}_{\mathrm{r}}$ no ambiente. Esse aumento significativo na criação de novo $\mathrm{N}_{\mathrm{r}}$ provocou um expressivo desequilíbrio no ciclo biogeoquímico do $\mathrm{N}$ e provocou uma série de impactos negativos ao ambiente e à saúde humana. ${ }^{30}$

Galloway e colaboradores publicaram em 2008 um trabalho relacionado às transformações ocorridas no ciclo do nitrogênio devido ao aumento massivo da disponibilidade de $\mathrm{N}_{\mathrm{r}}$ para o ambiente, estabelecendo seus padrões de distribuição ao redor do mundo e tentando apontar possíveis soluções. Os autores alertam para o fato de que em muitas regiões do globo onde ainda existe fome, há escassez de $\mathrm{N}$, enquanto regiões mais ricas possuem excesso desse nutriente. Os autores defenderam não somente a redução da produção de $\mathrm{N}_{\mathrm{r}}$ global, como também uma melhor distribuição desse ao redor do mundo. ${ }^{22}$ Erisman e colaboradores publicaram em 2013 um artigo de revisão no qual foram exploradas as consequências do excesso de $\mathrm{N}_{\mathrm{r}}$ aos ecossistemas aquáticos e terrestres, à saúde humana $\mathrm{e}$ à mudança climática. Os autores consideraram que mesmo que muitas evidências sustentem o efeito cascata dos compostos de $\mathrm{N}_{\mathrm{r}}$ no ambiente, ainda é grande a variabilidade espacial e temporal relativa à sua escassez, excesso, fluxos, fontes e efeitos. Os autores destacam que dados adicionais ainda são necessários para que se quantifique cada etapa da cascata para melhor orientar decisões de cunho político e normativo para redução do $\mathrm{N}_{\mathrm{r}}{ }^{15}$ Fowler e colaboradores estimaram que as atividades antrópicas são responsáveis por metade do nitrogênio fixado globalmente. Apontam ainda que as emissões de amônia, proveniente dos fertilizantes nitrogenados utilizados na agricultura, somada às emissões de óxidos de nitrogênio, provenientes de combustão, contribuem para a entrada de $100 \mathrm{Tg}$ ano ${ }^{-1}$ de $\mathrm{N}_{\mathrm{r}}$ na atmosfera, o qual é então transportado através do globo e processado na atmosfera, gerando poluentes secundários, tais como ozônio e aerossol secundário. ${ }^{31}$

Outra grande dificuldade que surge para o pleno entendimento dos efeitos do $\mathrm{N}_{\mathrm{r}}$ no ambiente é considerar que os processos de transformação ocorridos dentro do ciclo são fortemente influenciados por outros processos ambientais dinâmicos. Johan Rockström e colaboradores publicaram em 2009 um trabalho no qual buscaram identificar os processos ambientais essenciais do planeta Terra e estabelecer seus limites planetários, ou seja, limiares que se ultrapassados, poderiam gerar impactos ambientais acima da capacidade de regeneração do planeta, ameaçando a existência de um espaço operacional seguro para a humanidade. Os processos ambientais essenciais apontados pelos autores foram: i. mudanças climáticas, ii. taxa de perda de biodiversidade (terrestre e marinha), iii. interferência no ciclo do nitrogênio e do fósforo, iv. depleção do ozônio estratosférico, v. acidificação dos oceanos, vi. uso global de água doce, vii. mudanças no uso da terra, viii. poluição química e ix. carga atmosférica de aerossóis. ${ }^{25}$ Embora os limites planetários sejam descritos no artigo em termos de quantidades individuais e processos separados, eles estão fortemente relacionados. Se um limite é transgredido, os demais processos também são afetados. Cabe ressaltar que na visão daqueles autores o limiar suportável para o planeta associado ao ciclo do nitrogênio já havia sido excedido.

O entendimento de como os compostos de $\mathrm{N}_{\mathrm{r}}$ participam em cada um dos processos ambientais levantados por Rockström é bastante 
complexo. Os inúmeros fatores ambientais envolvidos, a dinâmica desses compostos no ambiente e a inter-relação existente torna o assunto desafiador. Dentre os processos ambientais essenciais citados que estão diretamente ligados à emissão de gases de $\mathrm{N}_{\mathrm{r}}$ e que sequer pôde ter qualquer limite numérico estabelecido devido à falta de dados disponíveis, está a formação de aerossol atmosférico. Aerossóis de nitrogênio são formados na atmosfera e suas principais espécies precursoras são amônia e ácido nítrico. Estima-se que aerossóis de nitrato se tornem mais importantes na atmosfera futura, devido ao aumento das emissões de precursores de nitrato para a atmosfera e ao declínio da emissão de dióxido de enxofre, o precursor dos aerossóis de sulfato em grandes regiões do planeta. ${ }^{32}$

A ampliação do conhecimento relacionado ao aerossol atmosférico contendo nitrogênio é de fundamental importância para o entendimento do balanço radiativo global, da formação de nuvens e precipitação, dos efeitos à visibilidade e à saúde humana. O interesse relacionado ao estudo dos aerossóis atmosféricos tem se tornado crescente, especialmente nos últimos 30 anos (Figura 2). Uma busca realizada na literatura através da base de dados Web of Science mostrou que o número de trabalhos relacionados ao termo "atmospheric aerosol", em português "aerossol atmosférico", atingiu a marca de 36105 publicações, sendo que mais de $95 \%$ delas ocorreram nos últimos 20 anos (de 1999 a 2019). Em contrapartida, o levantamento bibliográfico direcionado ao aerossol nitrogenado ("nitrogen aerosol", "nitrate aerosol" ou "ammonium aerosol") retorna um volume bem menor de trabalhos, indicando o quanto esse tema ainda é pouco explorado.

Assim, o presente artigo de revisão foi elaborado buscando-se estabelecer um paralelo entre as emissões de gases de $\mathrm{N}_{\mathrm{r}}$ e a formação de aerossol atmosférico, fornecendo uma visão geral sobre quais são e como ocorrem as principais reações de formação do aerossol, seus processos de crescimento e suas implicações ao meio ambiente e à saúde humana.

\section{GASES DE NITROGÊNIO REATIVO PRECURSORES DO AEROSSOL ATMOSFÉRICO}

Uma vez emitidos para a atmosfera, quer por fontes naturais ou antrópicas, os gases de $\mathrm{N}_{\mathrm{r}}$ passam pelo processo de conversão gás-partícula. Os gases de $\mathrm{N}_{\mathrm{r}}$ que efetivamente participam na formação de aerossol atmosférico compreendem basicamente a amônia, e as espécies gasosas que foram oxidadas a partir monóxido de nitrogênio para formar o ácido nítrico. $\mathrm{O}$ gás $\mathrm{N}_{2} \mathrm{O}$, óxido nitroso, apesar de considerado um gás de $\mathrm{N}_{\mathrm{r}}$, não passa por processos de transformação na troposfera, devido a sua baixa reatividade química. Em contraste com os demais gases de nitrogênio reativo, que possuem tempo de residência de algumas horas na atmosfera, o $\mathrm{N}_{2} \mathrm{O}$ possui tempo de residência de 114 anos, o que contribui para sua acumulação na atmosfera. A estabilidade desse gás na troposfera possibilita que ele alcance a estratosfera, onde participa de reações que resultam na formação de $\mathrm{NO}_{x}$ estratosférico, os quais, por sua vez, catalisam a decomposição do ozônio. Além disso, devido a sua capacidade de interagir com radiação infravermelha, a molécula de $\mathrm{N}_{2} \mathrm{O}$ possui elevado potencial de aquecimento (296 vezes maior em relação ao $\mathrm{CO}_{2}$ ), o que contribui para o agravamento do efeito estufa. ${ }^{27}$ Portanto, apesar desses gases estarem interligados pelo ciclo biogeoquímico do nitrogênio, as emissões do gás $\mathrm{N}_{2} \mathrm{O}$ estão relacionadas à mudança climática global, com ação na estratosfera. Neste artigo, focaremos nos efeitos das emissões dos gases $\mathrm{NH}_{3}, \mathrm{HNO}_{3}, \mathrm{NO}$ e $\mathrm{NO}_{2}$, atuantes na formação de aerossol atmosférico na troposfera.

\section{Amônia $\left(\mathrm{NH}_{3}\right)$}

A amônia é um gás incolor à temperatura ambiente. Possui um odor pungente característico que é percebido em concentrações acima de $50 \mathrm{ppm}$ e é mais leve do que o ar atmosférico (densidade relativa $\mathrm{NH}_{3}-\mathrm{Ar}=0,597$ à $101,325 \mathrm{kPa}$ e $25^{\circ} \mathrm{C}$ ). Apresenta pontos de fusão e ebulição de $-77,7$ e $-33,35^{\circ} \mathrm{C}$, respectivamente, e é bastante solúvel em água: à $20^{\circ} \mathrm{C}$ e $101,325 \mathrm{kPa}$, um volume de água dissolve 702 volumes de amônia, resultando em uma solução alcalina. Apesar disso, a amônia pode ser facilmente removida da água através de fervura. ${ }^{33,34}$

As principais fontes de amônia para atmosfera incluem processos naturais (decomposição da matéria orgânica) e uma variedade de atividades antrópicas. As emissões antrópicas de $\mathrm{NH}_{3}$ representam $36 \%$ do $\mathrm{N}$ anual total emitido (ou 43 milhões de toneladas de $\mathrm{N}$ por ano), considerando-se as fontes naturais. ${ }^{35} \mathrm{~A}$ agricultura é o setor

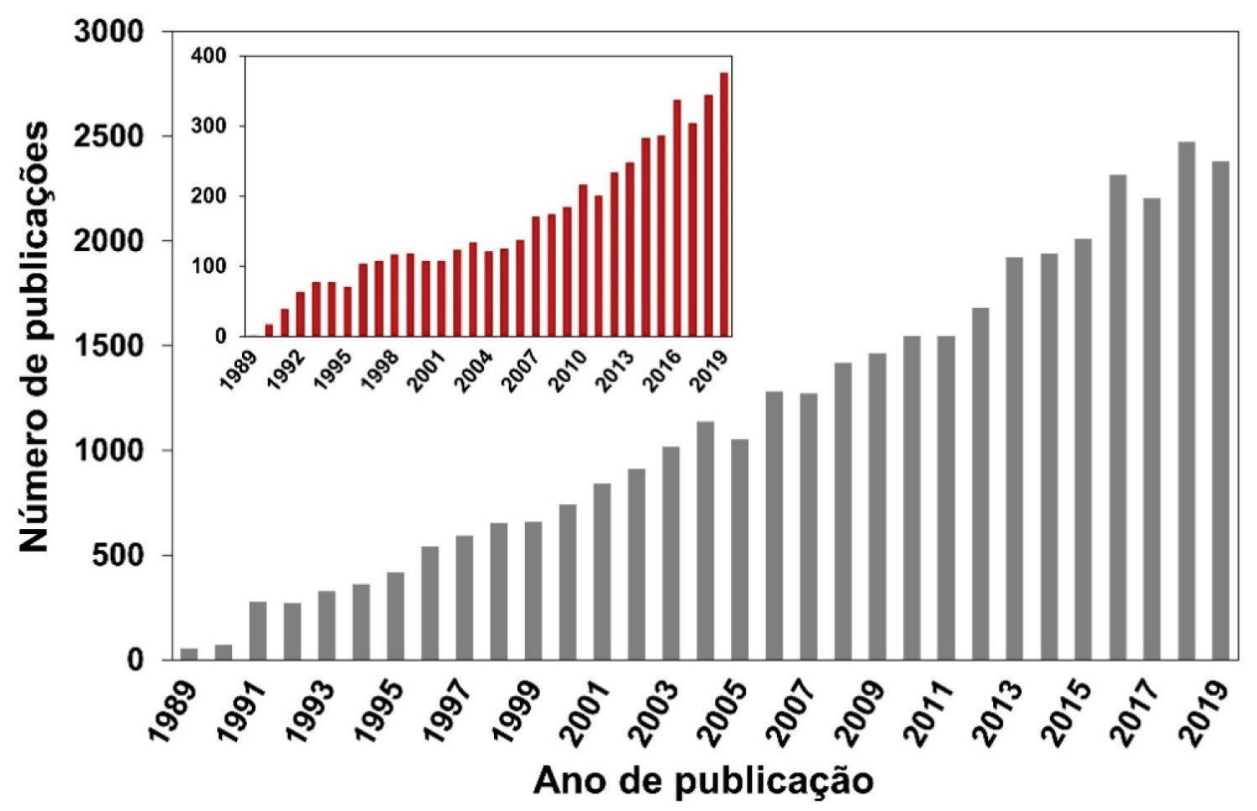

Figura 2. Trabalhos científicos publicados nos últimos 30 anos relacionadas ao tema "atmospheric aerosol" (de 1989 a 2019). Inserção: Trabalhos científicos relacionados ao tema "nitrogen aerossol" publicados no mesmo período. Levantamento bibliográfico realizado em 01 de abril de 2020 utilizando a base de dados Web of Science 
responsável pela maior parte da amônia emitida para o ambiente, no qual ela é volatilizada a partir de dejetos animais e pela aplicação de fertilizantes nitrogenados sintéticos para adubação de lavouras. ${ }^{36} \mathrm{~A}$ criação de animais pela pecuária intensiva de bovinos, suínos e aves é responsável por parte significativa da emissão de amônia em áreas rurais. Cerca de $10 \%$ do $\mathrm{N}$ utilizado para alimentação do gado de corte é convertido em proteína animal consumível; o restante do $\mathrm{N}$ é eliminado nas fezes $(30 \%)$ e urina $(60 \%)$ do animal. ${ }^{37} \mathrm{O}$ potencial da amônia emitida por esse setor torna-se preocupante quando as estatísticas relativas ao tamanho dos rebanhos ao redor do mundo são contabilizadas. De acordo com um relatório publicado em 2019 pela Food and Agriculture Organization of the United Nations (FAO), em 2017, o rebanho mundial de bovinos chegou a 1,49 bilhões de cabeças, enquanto que o rebanho de suínos era da ordem de 1,0 bilhão; além desses, somam-se 1,2 bilhões de ovelhas e cordeiros, 1,2 bilhões de patos e 1,0 bilhão de cabras. Esses números tornam-se relativamente pequenos quando comparados a população de frangos de corte e de galinhas para produção de ovos - 22,8 bilhões de animais. ${ }^{38,39}$ Inventários recentes mostram que o setor agropecuário responde por cerca de $80-85 \%$ do total da amônia emitida, sendo que dessa fatia, cerca de 9-20\% são devidos à aplicação de fertilizantes nitrogenados. ${ }^{40-42}$ Outras fontes minoritárias de amônia para o ambiente incluem: queima de biomassa (incêndios florestais), estações de tratamento de esgoto, emissões veiculares e emissões industriais (queima de combustível fóssil). ${ }^{35}$

A amônia é considerada o principal gás de caráter básico existente na atmosfera. Por essa razão, possui uma função essencial, que é neutralizar a acidez causada por gases ácidos e partículas ácidas da atmosfera. Devido a essa característica, a amônia tem sido apontada como principal agente químico envolvido no processo de nucleação de novas partículas na atmosfera. ${ }^{43}$

Os modelos sobre a formação de novas partículas na atmosfera são bastante limitados devido à falta de métodos físicos e químicos capazes de detectar e caracterizar o processo de nucleação de novas partículas. Até pouco tempo atrás não era possível realizar a detecção de partículas menores que $10 \mathrm{~nm}$, que equivale a uma partícula contendo aproximadamente 10000 moléculas. A partir de 2010, instrumentos capazes de detectar partículas da ordem de $3 \mathrm{~nm}$ foram desenvolvidos. Apesar desse avanço tecnológico, estima-se um tempo de "atraso" que pode chegar até 4 horas entre a ocorrência da nucleação e a detecção, devido ao tempo necessário para o crescimento das partículas a um tamanho detectável pelos instrumentos. ${ }^{44,45}$

Dentre os principais modelos propostos para a formação de novas partículas, dois deles demonstraram ser os mais relevantes: i. a nucleação binária de ácido sulfúrico $\left(\mathrm{H}_{2} \mathrm{SO}_{4}\right)$ e água, que ocorre quando a pressão de vapor do ácido sulfúrico excede a pressão de vapor de saturação da mistura água-ácido sulfúrico; e ii. a nucleação ternária, que ocorre quando o mecanismo de nucleação água-ácido sulfúrico envolve uma terceira molécula. A terceira molécula mais provável nesse último modelo é a amônia, que é ubíqua na troposfera e tem demonstrado aumentar as taxas de nucleação do ácido sulfúrico. ${ }^{44,46}$ Estudos sugerem que a presença de amônia em concentração de cerca de 100 ppt aumenta a taxa de nucleação de partículas de ácido sulfúrico de 100 a 1000 vezes. ${ }^{47}$

A formação de novas partículas a partir da reação da amônia e ácido sulfúrico ocorre majoritariamente quando esse último está previamente adsorvido em partículas contendo água, uma vez que trata-se de um ácido fixo e que, portanto, possui apenas uma ínfima parte de suas moléculas em fase gás presentes na atmosfera em condições ambientais típicas. Diferentemente, a formação de novas partículas a partir da reação da amônia com ácidos voláteis, tais como o ácido nítrico $\left(\mathrm{HNO}_{3}\right)$, o ácido nitroso $\left(\mathrm{HNO}_{2}\right)$ e o ácido clorídrico $(\mathrm{HCl})$, pode ocorrer diretamente com ambos os reagentes na forma gasosa ou quando a espécie ácida encontra-se adsorvida em partículas contendo um componente aquoso. Todas essas reações (14) que produzem sais de amônio (via reação ácido-base), irão formar aerossóis que pertencem predominantemente à fração mais fina do material particulado (diâmetro aerodinâmico equivalente $<2,5 \mu \mathrm{m}$ ).

$$
\begin{aligned}
& \mathrm{NH}_{3}(g)+\mathrm{H}_{2} \mathrm{SO}_{4}(a q) \rightleftharpoons \mathrm{NH}_{4} \mathrm{HSO}_{4}(s) \rightleftharpoons \mathrm{NH}_{4}^{+}(a q)+\mathrm{H}^{+}(a q)+\mathrm{SO}_{4}^{2-}(a q)(1 \mathrm{a}) \\
& 2 \mathrm{NH}_{3}(g)+\mathrm{H}_{2} \mathrm{SO}_{4}(a q) \rightleftharpoons\left(\mathrm{NH}_{4}\right)_{2} \mathrm{SO}_{4}(s) \rightleftharpoons 2 \mathrm{NH}_{4}^{+}(a q)+\mathrm{SO}_{4}^{2-}(a q)(1 \mathrm{~b}) \\
& \mathrm{NH}_{3}(g)+\mathrm{HNO}_{3}(g) \rightleftharpoons \mathrm{NH}_{4} \mathrm{NO}_{3}(s) \rightleftharpoons \mathrm{NH}_{4}^{+}(a q)+\mathrm{NO}_{3}^{-}(a q)(2) \\
& \mathrm{NH}_{3}(g)+\mathrm{HNO}_{2}(g) \rightleftharpoons \mathrm{NH}_{4} \mathrm{NO}_{2}(s) \rightleftharpoons \mathrm{NH}_{4}^{+}(a q)+\mathrm{NO}_{2}^{-}(a q)(3) \\
& \mathrm{NH}_{3}(g)+\mathrm{HCl}(g) \rightleftharpoons \mathrm{NH}_{4} \mathrm{Cl}(\mathrm{s}) \rightleftharpoons \mathrm{NH}_{4}^{+}(a q)+\mathrm{Cl}^{-}(a q)
\end{aligned}
$$

As partículas recém formadas nessas reações passam então a incorporar água em sua composição como resultado da disponibilidade de vapor de água na atmosfera. Dessa forma, uma partícula de aerossol genérica pode ser descrita como um agregado de compostos químicos diversos, entre eles, sais sólidos em equilíbrio com espécies iônicas dissolvidas; ao redor da partícula, um filme aquoso mantém o agregado unido. O teor de água em uma partícula de aerossol depende de dois fatores: da composição química da partícula e da umidade relativa do ar (UR, expressa em porcentagem). A UR é a razão percentual entre a pressão parcial de vapor da água no ar (g/kg) e a pressão de vapor esperada nas condições de saturação, a uma determinada temperatura. A condição de saturação é alcançada quando se estabelece o equilíbrio entre a água na fase vapor da atmosfera e a forma líquida presente na partícula. ${ }^{48}$

A composição química das partículas pode modificar o equilíbrio que se estabelece entre o vapor de água da atmosfera e a quantidade de água presente na partícula do aerossol, afetando o diâmetro aerodinâmico da partícula. Experimentos feitos na região rural do Estado de São Paulo entre 2010 e 2011 mostraram que a massa de partículas na fração de 1,0-3,0 $\mu$ m aumentou cerca de 60 vezes durante a noite no verão e apenas cerca de 2,5 vezes nas noites de inverno. A região do estudo é caracterizada por verões úmidos e invernos secos, com baixa UR durante o dia. O grande aumento da massa das partículas na faixa de tamanho $<3,0 \mu \mathrm{m}$ no verão poderia ser explicado por uma maior aglutinação de núcleos de aerossol e/ ou por uma maior condensação de vapores da atmosfera sobre as partículas nucleadas, especialmente vapor de água nas partículas contendo íons com características higroscópicas. Como as emissões de gases ácidos nucleadores de novas partículas diminuem à noite, o crescimento das partículas por aglutinação de partículas não poderia explicar o aumento de massa observado. Dessa forma, o aumento da massa das partículas nessa faixa de tamanho é, portanto, resultado do crescimento do filme de água ao redor da partícula, ocorrido como resultado da condensação de vapor de água. A maior absorção de água pelas partículas durante o verão, por sua vez, pode ser explicada pela ação de dois fatores: i. da umidade mais alta, e/ou ii. da existência de um aerossol de composição química diferente, com caráter mais higroscópico do que aquele observado durante o inverno. A análise química do material particulado coletado mostrou que, no verão, a composição das partículas era mais rica no íon amônio $\left(\mathrm{NH}_{4}^{+}\right)$, de característica muito higroscópica; já no inverno, as partículas apresentaram composição rica em potássio $\left(\mathrm{K}^{+}\right)$, íon menos higroscópico. $\mathrm{O}$ verão é a época típica de plantio na região do estudo, na qual ocorre a aplicação de fertilizantes nitrogenados. Uma vez aplicado no solo, parte do fertilizante nitrogenado é convertido em gás amônia, que volatiliza para a atmosfera, onde 
é finalmente convertido a íon amônio no processo de formação da partícula de aerossol. No inverno, por sua vez, a composição das partículas finas é mais rica no íon potássio $\left(\mathrm{K}^{+}\right)$, proveniente das emissões da queima de biomassa, que ocorrem com mais frequência durante a noite. As emissões de gases precursores durante a noite favorecem a nucleação de partículas e sua aglomeração, no entanto, a composição rica em potássio inibe a absorção de vapor de água pelas partículas resultando em menor crescimento da massa das partículas nessa época do ano. ${ }^{49,50}$

$\mathrm{O}$ equilíbrio entre o filme líquido que se forma ao redor de uma partícula de sal com o vapor de água presente na atmosfera pode ser deslocado de duas maneiras. A primeira delas se dá pela absorção do vapor de água da atmosfera pelo sal sólido, o que leva à dissolução de parte de seus íons e à formação de um tênue filme d'água ao redor da partícula; esse estágio é conhecido como ponto de deliquescência e é característico de composição de cada sal. O sulfato de amônio, por exemplo, apresenta um ponto de deliquescência em cerca de $75 \%$ de umidade relativa do ar, ponto a partir do qual, ele passa a absorver água do ambiente para formar um sal hidratado. O nitrato de amônio por sua vez, atinge seu ponto de deliquescência quando a umidade relativa do ar está em $62 \%$. Esse processo ocorre quando a pressão de vapor da água presente no ar atmosférico é maior que a pressão de vapor da água da solução salina formada em torno da partícula. Dependendo da umidade relativa, o sal pode absorver água em quantidade suficiente até que ocorra sua total solubilização. O processo contrário passa a ocorrer caso a pressão de vapor da água no ar diminua, como resultado de uma menor umidade relativa. Assim, a partícula passa a perder água para a atmosfera, num processo conhecido como eflorescência, também característico de cada sal..$^{51}$

O modelo de interação de uma partícula salina de sulfato de amônio com vapor de água da atmosfera é apresentado na Figura 3. Uma partícula sólida de sulfato de amônio passa a absorver água quando a umidade relativa do ar alcança o valor de aproximadamente $75 \%$ (ponto de deliquescência do sal); com o aumento progressivo da umidade relativa do ar, a solubilização total do cristal é alcançada, formando uma solução salina. Em caso de diminuição progressiva da umidade relativa do ar, a evaporação da água contida na partícula passa a ser predominante, resultando em uma partícula cada vez menor. Se a umidade relativa for suficientemente baixa para atingir o ponto de eflorescência do sal (umidade relativa de aproximadamente $35 \%$ para o sulfato de amônio), a perda de água pelo sal hidratado torna-se intensa, levando a partícula a assumir a aparência de um pó sólido. ${ }^{52}$

Estudos de deliquescência e eflorescência de sais são normalmente realizados em laboratório utilizando-se o sal puro. Entretanto, devido ao caráter multi-fase e multi-componente que as partículas atmosféricas comumente assumem, é provável que os valores dos pontos de deliquescência e eflorescência sofram alterações. ${ }^{53}$ Brooks e colaboradores realizaram uma série de experimentos visando verificar a influência de diferentes compostos orgânicos no ponto de deliquescência do sal sulfato de amônio. Os autores observaram que a presença de ácidos carboxílicos solúveis na mistura com sulfato de amônio causou a diminuição da deliquescência (menor umidade relativa) em comparação ao sal de sulfato de amônio puro; em contraste, os autores verificaram que a presença de ácidos carboxílicos pouco solúveis na mistura com o sal, não tiveram qualquer influência sobre o ponto de deliquescência do sulfato de amônio..$^{54}$

Souza e colaboradores determinaram a concentração numérica do aerossol atmosférico na região rural de Araraquara, entre agosto de 2011 e novembro de 2012. Os autores observaram uma significativa diminuição do número de partículas na faixa de diâmetro entre 25$100 \mathrm{~nm}$ (modo de Aitken) ao longo do dia e em todas as estações do ano, sendo esse efeito mais pronunciado durante o inverno. A variabilidade observada pode ser explicada pela maior temperatura diurna (em relação à noturna) e à menor umidade relativa do ar no inverno (em relação às demais estações). Essas condições ambientais propiciam a perda gradativa de água pelas partículas ao longo do dia, o que resulta na diminuição das partículas até uma faixa tamanho que não pode ser observada pelo equipamento de detecção. O aumento numérico de partículas com diâmetro na faixa de 25-100 nm voltou a ser observado durante à noite, quando a menor temperatura e maior umidade favorecem a reabsoção de água da atmosfera pelas partículas, fazendo com que cresçam até atingirem novamente a faixa de tamanho detectável pelo instrumento. ${ }^{53}$

Outro equilibrio que depende da UR é a nucleação de partículas

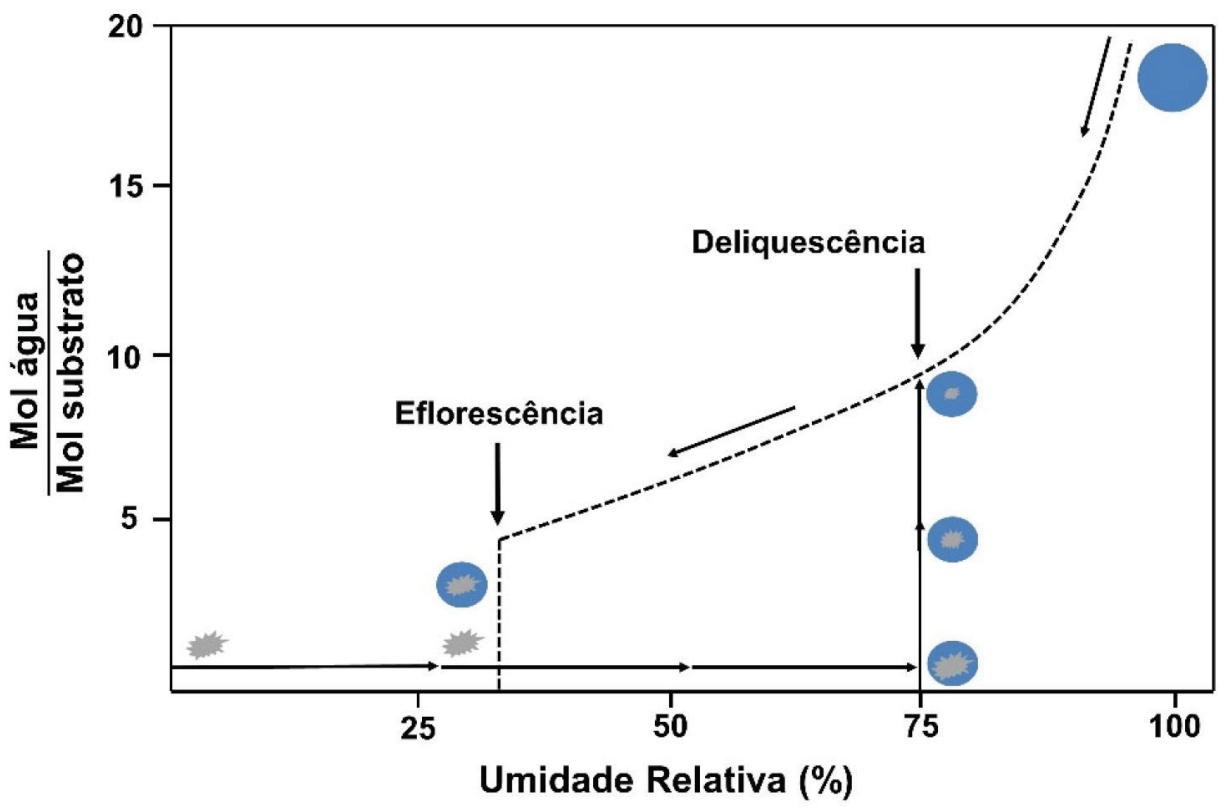

Figura 3. Representação esquemática dos processos de absorção e perda de água por uma partícula de sal de sulfato de amônio, demonstrando como o tamanho da partícula varia de acordo com a sua composição (que determina os pontos de deliquescência e eflorescência) e com a umidade relativa do ar (disponibilidade de água na atmosfera). Adaptado de Reid $2003^{51}$ e reproduzido com a permissão de The Royal Society of Chemistry 
a partir de precursores gasosos. A reação de neutralização de ácidos voláteis e amônia resulta na nucleação de uma partícula salina. Esse sal absorve vapor de água da atmosfera formando íons hidratados (Reação 5). Em condições de baixa umidade, o equilíbrio químico da reação se desloca para favorecer a regeneração dos precursores gasosos, que são mais estáveis nessas condições .

$$
\mathrm{NH}_{3}(g)+\mathrm{HX}(\mathrm{g}) \rightleftharpoons \mathrm{NH}_{4} X(s)+\mathrm{H}_{2} \mathrm{O}(\mathrm{l}) \rightleftharpoons \mathrm{NH}_{4}^{+}(a q)+X^{-}(a q)
$$

A pressão atmosférica é uma variável ambiental que também pode influenciar o equilíbrio químico dessas reações. Isso explica erros que ocorrem durante a amostragem de partículas de sais de amônio na atmosfera. As pressões negativas, resultantes do uso de bombas para aspiração do ar durante a amostragem em ambientes de baixa UR, podem favorecer a recomposição dos gases que formaram o aerossol. Como resultado, o aerossol coletado contém uma menor concentração de sais de amônio, em comparação ao que de fato está presente na atmosfera. Esse fato demonstra como as condições ambientais podem interferir na amostragem de partículas contendo sais de amônio em sua composição.

Reações de neutralização com sucessiva formação de material particulado fino, parecem ser, juntamente com as deposições seca e úmida, os meios de remoção mais comuns de gases ácidos e amônia na atmosfera. Estimativas das taxas de conversão de $\mathrm{NH}_{3}$ para $\mathrm{NH}_{4}^{+}$ variam entre $10^{3}-10^{5} \mathrm{~s}$. Essa conversão é mais efetiva na camada mais baixa da atmosfera, até cerca de 100 metros acima da superfície, e é muito mais rápida durante o dia do que durante a noite..$^{55,56}$

Existem ainda outros processos minoritários de remoção da amônia atmosférica. Na estratosfera, a amônia pode sofrer fotólise pela ação da radiação solar em comprimentos de onda abaixo de 220 $\mathrm{nm}$, levando à formação do radical amina $\left(\mathrm{NH}_{2}{ }^{\circ}\right)$, que atua no processo de depleção do ozônio estratosférico. ${ }^{57}$ Esse processo, no entanto, não tem efeito na formação de aerossol atmosférico. Na troposfera, em contrapartida, uma pequena quantidade da amônia atmosférica (cerca de $1 \%$ ) também reage com o radical hidroxila $(\mathrm{OH} \cdot)$ produzindo radicais amina, o que provavelmente ocorre conforme apresentado na Reação $6 .^{58}$

$\mathrm{NH}_{3}(g)+\mathrm{OH}^{\cdot}(\mathrm{g}) \rightleftharpoons \mathrm{NH}_{2}(\mathrm{~g})+\mathrm{H}_{2} \mathrm{O}(\mathrm{g})$

O tempo de vida médio da amônia em relação a sua reação com o radical hidroxila é de 72 dias, entretanto, o radical formado nessa reação possui tempo de vida de 30 segundos ao reagir com o oxigênio $\left(\mathrm{O}_{2}\right)$, e de apenas 2-3 segundos quando reage com $\mathrm{NO}, \mathrm{NO}_{2}$ ou $\mathrm{O}_{3}$ (Reações 7-9). ${ }^{58}$

$$
\begin{aligned}
& \mathrm{NH}_{2}(g)+\mathrm{NO}(g) \rightleftharpoons \mathrm{N}_{2}(g)+\mathrm{H}_{2} \mathrm{O}(\mathrm{g}) \\
& \mathrm{NH}_{2}(g)+\mathrm{NO}_{2}(g) \rightleftharpoons \mathrm{N}_{2} \mathrm{O}(g)+\mathrm{H}_{2} \mathrm{O}(g) \\
& \mathrm{NH}_{2}(g)+\mathrm{O}_{3}(g) \rightleftharpoons \mathrm{NO}(g)+\mathrm{H}_{2} \mathrm{O}(g)
\end{aligned}
$$

Nas reações 7 e 8, o radical amina atua como um agente redutor dos gases $\mathrm{NO}$ e $\mathrm{NO}_{2}$ resultando na formação de $\mathrm{N}_{2}$ (não-reativo) e $\mathrm{N}_{2} \mathrm{O}$ (espécie que não participa na formação de aerossol atmosférico). Entretanto, quando o radical amina reage com ozônio, o produto formado é o NO, que por sua vez, pode sofrer outras reações e participar na formação do aerossol atmosférico. Assim, a amônia pode ser considerada tanto um sorvedouro (Reações 7 e 8) como uma fonte (Reação 9) do $\mathrm{NO}_{\mathrm{x}}$ atmosférico. No entanto, incertezas quanto à cinética e distribuição espacial de $\mathrm{O}_{3}$ e $\mathrm{NO}_{\mathrm{x}}$ conduzem a uma estimativa de que somente cerca de $10 \%$ do $\mathrm{NO}_{x}$ atmosférico tenha como fonte a oxidação da amônia. ${ }^{34}$

\section{Espécies oxidadas de $\mathrm{N}_{\mathrm{r}}\left(\mathrm{NO}_{\mathrm{x}}\right.$ e $\left.\mathrm{HNO}_{3}\right)$}

Os óxidos de nitrogênio, $\mathrm{NO}$ e $\mathrm{NO}_{2}$, quantificados como $\mathrm{NO}_{x}$ $\left(\mathrm{NO}+\mathrm{NO}_{2}\right)$, são gases traço de nitrogênio altamente reativos, que desempenham um papel fundamental no controle da capacidade oxidativa da atmosfera, regulando as quantidades de ozônio, radicais hidroxila, compostos orgânicos voláteis, e outras espécies-chave presentes na atmosfera. ${ }^{59}$

$\mathrm{O}$ óxido nítrico, NO, é primariamente emitido para a atmosfera como produto de uma série de processos antrópicos e naturais, tais como, queima de combustíveis fósseis, queima de biomassa, descargas elétricas atmosféricas e atividade de microrganismos no solo. Emissões de NO provenientes do solo correspondem a aproximadamente $20 \%$ do total das emissões de NO para a atmosfera, e variam em função da atividade microbiana e das propriedades físico-químicas do solo. Esse composto é um sub-produto formado nos processos bioquímicos de nitrificação e desnitirificação, os quais são majoritariamente controlados pela temperatura, teor de água, $\mathrm{pH}$ e disponibilidade de $\mathrm{N}$ no solo. ${ }^{60,61} \mathrm{NO}$ também pode ser produzido pela fotólise de HONO, o qual também é emitido a partir da ação de bactérias do solo. ${ }^{62}$

Uma vez na atmosfera, o NO é rapidamente oxidado na atmosfera pelo ozônio (Reação 10) e, mais lentamente, pelo oxigênio (Reação 11), para formar o dióxido de nitrogênio, $\mathrm{NO}_{2}$. A oxidação do $\mathrm{NO}$ pelo $\mathrm{O}_{2}$ é termolecular (envolvendo a colisão de três moléculas), e leva 226 dias para oxidar $85 \%$ de 100 partes por bilhão de NO. O ozônio, em contrapartida, promove essa oxidação em apenas 18 segundos. ${ }^{63}$

O processo de oxidação do NO também pode ser promovido pela ação de outros compostos oxidantes presentes na atmosfera, tais como os radicais peróxido, $\mathrm{RO}_{2}^{*}$ (Reação 12). $\mathrm{O} \mathrm{NO}_{2}$ resultante, por sua vez, sofre fotólise durante o dia, regenerando o $\mathrm{NO}$ anteriormente consumido (Reação 13); a interconversão entre $\mathrm{NO}$ e $\mathrm{NO}_{2}$ atinge um estado estacionário em apenas alguns minutos durante o dia. ${ }^{59}$

$$
\begin{aligned}
& \mathrm{NO}(g)+\mathrm{O}_{3}(g) \rightarrow \mathrm{NO}_{2}(g)+\mathrm{O}_{2}(g) \\
& 2 \mathrm{NO}(g)+\mathrm{O}_{2}(g) \rightarrow 2 \mathrm{NO}_{2}(g) \\
& \mathrm{NO}(g)+\mathrm{RO}_{2}(g) \rightarrow \mathrm{NO}_{2}(g)+\mathrm{RO} \cdot(g) \\
& \mathrm{NO}_{2}(g)+h v(\lambda \leq 400 n m) \rightarrow \mathrm{NO}(g)+\mathrm{O}(g)
\end{aligned}
$$

O tempo de residência de $\mathrm{NO}_{x}$ na atmosfera é relativamente curto (aproximadamente 24 horas), o que sugere a existência de mecanismos eficientes atuando como sorvedouro desses compostos. $\mathrm{O}$ principal mecanismo de remoção de $\mathrm{NO}_{\mathrm{x}}$ ocorre a partir da oxidação de $\mathrm{NO}_{2}$, dando origem ao $\mathrm{HNO}_{3}$, o qual é eficazmente removido da atmosfera por processos de deposição seca e úmida. Durante o dia, em presença de luz solar, a reação de oxidação de $\mathrm{NO}_{2}$ é promovida por radicais hidroxila $\left(\mathrm{OH}^{*}\right)$, resultando diretamente na formação de $\mathrm{HNO}_{3}$ (Reação 14). Já durante a noite, a formação de ácido nítrico ocorre via hidrólise de $\mathrm{N}_{2} \mathrm{O}_{5}$, proveniente da reação entre $\mathrm{NO}_{2}$ e o radical nitrato $\left(\mathrm{NO}_{3}^{\circ}\right)$ (Reações 15-16); esse radical nitrato é instável em presença de luz solar, existindo somente durante a noite; sua formação ocorre via reação entre ozônio e $\mathrm{NO}_{2}$ (Reação 17). ${ }^{64}$

$$
\begin{aligned}
& \mathrm{NO}_{2}(g)+\mathrm{OH}^{\cdot}(g) \rightarrow \mathrm{HNO}_{3}(g) \\
& \mathrm{N}_{2} \mathrm{O}_{5}(g)+\mathrm{H}_{2} \mathrm{O}(\mathrm{l}) \rightarrow 2 \mathrm{HNO}_{3}(\mathrm{gq}) \\
& \mathrm{NO}_{2}(g)+\mathrm{NO}_{3}(g) \rightarrow \mathrm{N}_{2} \mathrm{O}_{5}(g) \\
& \mathrm{NO}_{2}(g)+\mathrm{O}_{3}(g) \rightarrow \mathrm{NO}_{3}(g)+\mathrm{O}_{2}(g)
\end{aligned}
$$


Uma vez na atmosfera, o $\mathrm{HNO}_{3}$ pode ser diretamente removido por processos de deposição seca e úmida ou, sofrer novas reações químicas a partir da interação, tanto com a amônia em fase homogênea como em fase heterogênea, após adsorção em partículas preexistentes. A partir da sequência de reações promovidas primordialmente pela molécula de $\mathrm{NO}_{2}$, é possível utilizar a concentração de $\mathrm{NO}_{2}$ atmosférico para prever a deposição das principais espécies de $\mathrm{N}_{\mathrm{r}}$ para o solo e águas superficiais. ${ }^{49}$

Além do $\mathrm{HNO}_{3}$, nitratos orgânicos, os quais incluem os peróxinitratos $\left(\mathrm{RO}_{2} \mathrm{NO}_{2}\right)$ e os alquil-nitratos mono e multifuncionais $\left(\mathrm{RONO}_{2}\right)$, também podem ser formados como produto das reações de $\mathrm{NO}_{\mathrm{x}}$ com produtos de oxidação de compostos orgânicos voláteis (COV).

Durante o dia, a produção química desses nitratos orgânicos iniciase com o ataque de um radical hidroxila sobre um hidrocarboneto saturado, seguido pela abstração de um hidrogênio e, pela adição quase imediata de uma molécula de $\mathrm{O}_{2}$, para gerar um radical $\mathrm{RO}_{2}$ (Reações 18 e 19). ${ }^{65}$

$$
\begin{aligned}
& R H(g)+\mathrm{OH}^{\cdot}(g) \rightarrow R^{\cdot}(g)+\mathrm{H}_{2} \mathrm{O}(g) \\
& R^{\cdot}(g)+\mathrm{O}_{2}(g) \rightarrow R O_{2}(g)
\end{aligned}
$$

Em seguida, na presença de $\mathrm{NO}_{x}$, o radical $\mathrm{RO}_{2}^{\bullet}$ reage com $\mathrm{NO}$ por duas vias de formação de produto (Reações 20a e 20b).

$R O_{2}(g)+N O(g) \rightarrow R O \cdot(g)+N_{2}(g)$

$\mathrm{RO}_{2}(g)+\mathrm{NO}(g) \rightarrow \mathrm{RONO}_{2}(g)$

A Reação 20a é a via dominante, pela qual os ciclos catalíticos de $\mathrm{NO}_{x}$ e $\mathrm{HO}_{x}$ se propagam, com produtos que são $\mathrm{NO}_{2}$ e um radical alcóxi. A via minoritária, 20b, é de terminação de cadeia, e forma um nitrato orgânico monofuncional estável. ${ }^{65}$

Radicais $\mathrm{RO}_{2}^{*}$ também reagem com $\mathrm{NO}_{2}$ (Reação 21) para formar peróxi-nitratos $\left(\mathrm{RO}_{2} \mathrm{NO}_{2}\right)$ em uma escala de tempo comparável à formação de $\mathrm{RONO}_{2}$. Os peróxi-nitratos são termicamente lábeis e podem rapidamente se dissociar à temperatura ambiente. Geralmente, a formação de $\mathrm{RO}_{2} \mathrm{NO}_{2}$ não afeta a formação de $\mathrm{RONO}_{2}$, exceto pela alteração da disponibilidade de $\mathrm{NO}_{x} \cdot{ }^{66,67}$

$\mathrm{RO}_{2}(g)+\mathrm{NO}_{2}(g) \rightleftharpoons \mathrm{RO}_{2} \mathrm{NO}_{2}(g)$

Uma vez formados na atmosfera, esses nitratos orgânicos podem ser transportados por massas de ar, sofrer outras reações químicas, passar por processos de deposição ou ser incorporados ao aerossol atmosférico. O tempo de residência relativamente longo de formas insolúveis, tais como de alguns peróxi-nitratos, permite que eles sejam transportados ao redor do globo, afetando a disponibilidade de $\mathrm{NO}_{x}$ e a abundância de ozônio na troposfera remota. ${ }^{68} \mathrm{O}$ exemplo mais conhecido é do composto conhecido como PAN $\left(\mathrm{CH}_{3} \mathrm{CH}_{2} \mathrm{O}_{2} \mathrm{NO}_{2}\right.$, nitrato de peroxiacetila). Sob diferentes condições ambientais, o equilíbrio representado pela Reação 22 pode ser deslocado para favorecer a regeneração do $\mathrm{NO}_{2}$ em um local muito distante da fonte de emissão inicial de $\mathrm{NO}_{\mathrm{x}}$.

$$
\mathrm{CH}_{3} \mathrm{CH}_{2} \mathrm{O}_{2}(\mathrm{~g})+\mathrm{NO}_{2}(\mathrm{~g}) \rightleftharpoons \mathrm{CH}_{3} \mathrm{CH}_{2} \mathrm{O}_{2} \mathrm{NO}_{2}(\mathrm{~g})
$$

Esse mecanismo de transporte por longas distâncias mostra o quão complexa é a química de $\mathrm{NO}_{\mathrm{x}}$ e seu efeito sobre a formação atmosférica de aerossóis, não só a nível local, como também em regiões distantes do ponto onde a emissão se originou. A Figura 4 apresenta uma síntese das principais reações sofridas por $\mathrm{NO}_{\mathrm{x}}$ na atmosfera, descritas nesta seção.

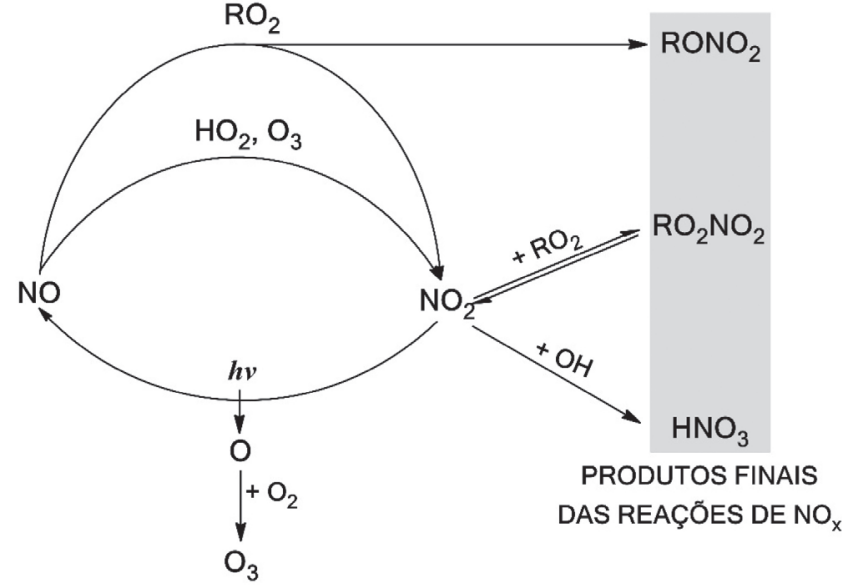

Figura 4. Reações de interconversão dos óxidos de nitrogênio $\mathrm{NO}_{\text {e }} \mathrm{NO}_{2}$ e os produtos finais resultantes dos processos de remoção do $\mathrm{NO}_{x}$ atmosférico. Adaptado e reproduzido com a permissão de Perring e colaboradores. ${ }^{65}$ Copyright 2013 American Chemical Society

\section{IMPLICAÇÕES AMBIENTAIS}

\section{Saúde}

O aerossol secundário resultante das reações de neutralização com amônia pertencem à fração mais fina do aerossol atmosférico $(<2,5 \mu \mathrm{m})$. O conhecimento atual já permite reconhecer o aerossol atmosférico secundário menor que $2,5 \mu \mathrm{m}$, como um dos principais agentes associados a piora da qualidade de vida das pessoas e à problemas ambientais, com especial efeito negativo atribuído ao material particulado contendo nitrogênio em sua composição. ${ }^{69}$ Os efeitos à saúde de pessoas expostas a esse tipo de material particulado fino tem origem nas características do sistema respiratório humano e em sua capacidade de filtrar e reter partículas. Partículas de diâmetro aerodinâmico equivalente igual ou inferior a $10 \mu \mathrm{m}$, convencionalmente denominadas $\mathrm{MP}_{10}$, possuem tamanho pequeno suficiente para serem inaladas, porém grande o suficiente para ficarem retidas no trato respiratório superior, o qual é formado por órgãos localizados fora da caixa torácica, incluindo nariz, laringe, faringe e parte superior da traqueia. Já as partículas com diâmetros inferiores a 2,5 $\mu \mathrm{m}\left(\mathrm{MP}_{2,5}\right)$, possuem dimensão pequena o suficiente para ultrapassarem as barreiras de proteção do trato respiratório superior. Assim, possuem potencial para atingir os pulmões a nível alveolar, onde os mecanismos de expulsão desses poluentes não é eficiente. ${ }^{70,71}$ Por essa razão, medidas de $\mathrm{MP}_{10}$ e $\mathrm{MP}_{2,5}$ tornaram-se indicadores da qualidade do ar atmosférico. Esses indicadores são adotados universalmente e foram escolhidos em razão da frequência de ocorrência e seus efeitos adversos. ${ }^{72}$

Trabalhos recentes da literatura descrevem como o aumento na formação do aerossol fino afeta negativamente a qualidade do ar e a saúde da população exposta a uma atmosfera poluída. Muitos deles demonstram que possíveis políticas de redução dos compostos precursores do $\mathrm{MP}_{2,5}$, em especial a amônia, podem melhorar a qualidade do ar, trazer benefícios econômicos e evitar mortes prematuras.

Giannadaki e colaboradores utilizaram modelos matemáticos para estimar os benefícios econômicos e à saúde humana advindos da redução das emissões agrícolas associadas à amônia, uma vez que essas emissões contribuem fortemente para a poluição do ar pela formação de material particulado fino $\left(\mathrm{MP}_{2.5}\right)$. Os autores relatam que uma redução de $50 \%$ nas emissões de amônia advindas da agricultura poderia prevenir cerca de 200 mil mortes por ano nos 59 
países que foram incluídos no estudo, além de trazer uma economia de muitos bilhões de dólares. ${ }^{73}$ Pozzer e colaboradores empregaram modelos climáticos globais para avaliar os impactos dos poluentes provenientes da agricultura sobre a formação de material particulado fino $\left(\mathrm{MP}_{2,5}\right)$. As simulações do estudo revelaram que uma forte redução na formação do material particulado fino $\left(\mathrm{MP}_{2,5}\right)$ poderia ser conseguida pela diminuição das emissões provenientes da agricultura, especialmente da amônia advinda do fertilizante nitrogenado e dos rebanhos animais. Os autores também relatam que uma possível diminuição nas emissões agrícolas levaria a uma diminuição do $\mathrm{pH}$ do aerossol atmosférico, como resultado da diminuição do aerossol de amônio, o qual afeta o equilíbrio químico heterogêneo da fase sólido-líquido. $^{74}$

Julin e colaboradores simularam a resposta da concentração numérica de partículas sobre a Europa a partir da implementação de futuras diretrizes ambientais para redução da emissão de compostos precursores do aerossol (incluindo a amônia). No trabalho, os autores utilizaram um modelo químico de transporte e consideraram três diferentes cenários de emissões (legislação vigente, emissões reduzidas, máxima redução de emissão tecnicamente viável). Os resultados obtidos em todos os cenários demonstram que futuras reduções nas emissões dos compostos precursores resultariam em uma diminuição substancial (10-50\%) na concentração numérica de partículas finas sobre a Europa. Com base nos resultados, os autores concluem que o controle das emissões provenientes da agricultura, principal fonte de espécies precursoras, representa uma forma efetiva para a diminuição do número de partículas finas na atmosfera. ${ }^{75}$

Lu e colaboradores investigaram o impacto à saúde relacionado ao aumento na formação de $\mathrm{MP}_{2,5}$ devido à utilização de amônia como fonte de hidrogênio, utilizado para geração de energia na Região de Kanto, região mais populosa do Japão. Utilizando um modelo matemático de transporte, os autores verificaram que se $20 \%$ da eletricidade dessa região fosse proveniente dessa fonte, o $\mathrm{MP}_{2,5}$ decorrente da decomposição incompleta da amônia teria sua concentração aumentada em $11,7 \%$ no inverno e $3,5 \%$ no verão, resultando em 351 mortes prematuras por ano devido à poluição do ar. $^{76}$

Thakrar e colaboradores estimaram os impactos econômicos e à saúde decorrentes da utilização de "switchgrass", gramínea nativa da América do Norte, como matéria-prima celulósica para produção de etanol. Os autores investigaram diferentes cenários de produção, rendimento e aplicação de fertilizantes nitrogenados em diferentes regiões dos Estados Unidos em seus modelos. Como resultados, os autores verificaram que os principais impactos à qualidade do ar na produção de switchgrass seria advindo do aumento nas emissões de $\mathrm{NH}_{3}$ proveniente do fertilizante nitrogenado, devido sua ação precursora na formação de material particulado fino $\left(\mathrm{MP}_{2,5}\right)$. Os autores elencam ainda quais seriam as melhores condições (locais de plantio, dosagens, tipo de fertilizante) na produção de switchgrass para obtenção de melhor custo-benefício e avaliação da viabilidade. ${ }^{77}$

Hristov estimou a contribuição da amônia emitida nas operações de alimentação animal para a formação de $\mathrm{MP}_{2,5}$ nos Estados Unidos. Considerando diferentes regiões e condições climáticas, o autor estimou que o $\mathrm{MP}_{2.5}$ formado pela amônia emitida a partir de operações pecuárias contribuiu em média de 5 a $11 \%$ do total de concentrações de $\mathrm{MP}_{2,5} \mathrm{O}$ autor ressalta ainda que em determinadas regiões e em clima frio, a contribuição do setor de criação de animais para a concentração atmosférica total de $\mathrm{MP}_{2.5}$ poderia chegar a $20 \% .^{78}$

A grave pandemia de COVID-19 ocorrida em 2020 fez com que severas medidas de redução de atividades produtivas e de mobilidade social fossem adotadas ao redor do mundo, com o objetivo de conter a propagação do vírus causador. Com a redução nas emissões de poluentes, uma drástica queda nos níveis de poluição atmosférica foram também observados. No Marrocos, Otmani e colaboradores avaliaram as mudanças ocorridas nos níveis de $\mathrm{MP}_{10}, \mathrm{NO}_{2}$ e $\mathrm{SO}_{2}$ após o início do período de confinamento na cidade de Salé. Os autores observaram que não só os níveis desses poluentes foram drasticamente reduzidos (queda de $75 \%, 49 \%$ e $96 \%$, para $\mathrm{MP}_{10}, \mathrm{SO}_{2}$ e $\mathrm{NO}_{2}$, respectivamente) em comparação ao período pré-pandemia, bem como mudanças nas trajetórias das massas de ar entre esses dois períodos foram observadas. ${ }^{79}$ Bao e colaboradores utilizaram os dados de concentrações de diversos poluentes atmosféricos $\left(\mathrm{SO}_{2}, \mathrm{MP}_{2,5}\right.$, $\mathrm{MP}_{10}, \mathrm{NO}_{2}$ e $\mathrm{CO}$ ) de 44 cidades chinesas, com o objetivo de avaliar como, e em que extensão, as medidas restritivas de deslocamento afetaram a qualidade do ar. Reduções significativas nos níveis de todos os poluentes foram observadas em todas as cidades do estudo. ${ }^{80}$ No Brasil, Nakada e colaboradores analisaram os dados de quatro estações de monitoramento da qualidade do ar localizadas na cidade de São Paulo durante o período de confinamento parcial, adotado na cidade. Os dados foram comparados com a média mensal de concentração dos poluentes de cinco anos anteriores e com a média mensal de quatro semanas anteriores à adoção das restrições. No geral, uma drástica redução nos níveis de $\mathrm{NO}, \mathrm{NO}_{2}$ e CO foram observadas (77,3\%, 54,3\% e 64,8\%, respectivamente), em comparação com os níveis dos períodos pré-confinamento. Em contrapartida, os autores observaram um aumento de aproximadamente $30 \%$ na concentração de ozônio nas áreas urbanas, provavelmente relacionado à diminuição nos níveis de $\mathrm{NO} .{ }^{81} \mathrm{Krecl}$ e colaboradores também verificaram quedas substanciais nos níveis de $\mathrm{NO}_{\mathrm{x}}$ em todas as 13 estações de monitoramento incluídas no estudo, realizado na cidade de São Paulo. As reduções de $\mathrm{NO}_{\mathrm{x}}$ variaram entre 34 e $68 \%{ }^{82}$

Apesar dos índices de qualidade do ar em todas as regiões reportadas apresentarem melhoras significativas a partir da implementação das medidas de confinamento, é importante destacar que eles foram obtidos em um contexto de exceção devido à pandemia, e que a manutenção desses índices não é sustentável a longo-prazo. No entanto, os dados obtidos nesse período demonstram que possíveis mudanças nos modelos de transporte urbano e na redução do consumo, teriam consequências positivas para redução da emissão de compostos de $\mathrm{N}_{\mathrm{r}}$ e na diminuição da poluição atmosférica como um todo.

A relação entre a poluição atmosférica causada por compostos de $\mathrm{N}_{\mathrm{r}}$ e o possível agravamento da fatalidade causada pela COVID-19 também vem sendo investigada. Ogen examinou a relação entre a exposição de longo prazo à diferentes níveis de concentração de $\mathrm{NO}_{2}$ e as taxas de fatalidade por COVID-19. Utilizando dados de satélite e modelos atmosféricos, o autor mapeou a distribuição troposférica do $\mathrm{NO}_{2}$ e a capacidade de dispersão da poluição, combinando essas informações aos dados referentes ao número de casos e mortes provenientes de 66 regiões administrativas da Itália, Espanha, França e Alemanha. O autor observou que $78 \%$ das fatalidades se concentraram em apenas 5 regiões, que apresentavam as maiores concentrações de $\mathrm{NO}_{2}$ combinadas à uma baixa capacidade de dispersão atmosférica. Esses resultados, de acordo com o autor, indicam que a exposição de longo prazo a esse poluente pode ser um dos agravantes mais importantes para a fatalidade causada pela COVID-19 nessas regiões e, talvez, ao redor do mundo. ${ }^{83}$ Similarmente, Wu e colaboradores investigaram se a exposição de longo prazo ao $\mathrm{MP}_{2,5}$ está associada com um maior risco de morte por COVID-19 nos Estados Unidos. Para tal, os autores utilizaram os dados de número de mortes registrados pela John Hopkins University referente a mais de 3000 condados (o que representou $98 \%$ da população), bem como os níveis de exposição de longo prazo a $\mathrm{MP}_{2,5}$ de cada região. Os autores concluíram que o aumento de $1 \mu \mathrm{g} \mathrm{m}^{-3}$ nos níveis de $\mathrm{MP}_{2,5}$ está associado com um aumento de $8 \%$ na taxa de mortalidade por COVID- $19 .{ }^{5}$ 


\section{Clima}

O termo forçante radiativa é definido como a perturbação do balanço de energia do sistema Terra-atmosfera. Ele é medido em unidades de energia por unidade de área (watts por metro quadrado: $\mathrm{W} \mathrm{m}^{-2}$ ) e fornece uma medida quantitativa do potencial de um determinado mecanismo para aquecer ou resfriar a atmosfera do planeta. O estado de referência para essa medida, adotado pelo Intergovernmental Panel on Climate Change (IPCC), foi o início da Revolução Industrial ${ }^{84}$ Dentre os diversos efeitos que tem influência sobre a forçante radiativa do planeta, está o aerossol atmosférico ${ }^{85}$

Os aerossóis podem influenciar na forçante radiativa líquida do planeta de modo direto e indireto. Eles são capazes de absorver ou espalhar a radiação dependendo de sua composição química e tamanho. Os aerossóis com propriedades de espalhamento de radiação têm um efeito de resfriamento do clima, enquanto que aerossóis com propriedades de absorção, aerossóis contendo partículas escuras de carbono negro ou poeiras minerais, tem um efeito de aquecimento da atmosfera. Esse é o chamado efeito direto da forçante radiativa dos aerossóis no clima do planeta. ${ }^{86,87}$

Os aerossóis também afetam o balanço térmico da atmosfera através de seu importante papel de formar núcleos de condensação de nuvens ( $\mathrm{NCN})$. O aumento da concentração numérica de aerossóis resulta em uma maior concentração numérica de gotículas existentes na atmosfera. Como consequência, um aumento da reflexão da radiação solar que retorna ao espaço ocorre, produzindo um efeito de resfriamento da atmosfera. O aumento na carga de aerossóis atmosféricos também leva à formação de gotículas de nuvem com raio efetivo menor, o que ocasiona uma diminuição da eficiência de precipitação. Trabalhos da literatura relatam que o aumento da carga de aerossóis atmosféricos provocou a inibição de precipitações, devido à diminuição do raio das gotículas de nuvem nas regiões estudadas. ${ }^{88-90}$ A supressão a precipitação aumenta o tempo de vida da nuvem na atmosfera e, portanto a quantidade de nuvens. Esse é o chamado segundo efeito indireto da forçante radiativa dos aerossóis para o clima do planeta.

A formação de aerossóis que atuem núcleos de condensação de nuvens (NCN), depende tanto da sua composição química como da ocorrência do processo de nucleação de partículas. A amônia possui um papel relevante nesse sentido, já que participa de um dos principais mecanismos de nucleação de aerossóis (nucleação ternária), além de ser um íon com propriedades higroscópicas, o que contribui para a condensação de vapor de água sobre a partícula, e portanto, para a formação de núcleos de condesação de nuvens.

\section{Dispersão de nutrientes}

Os aerossóis contendo nitrogênio em sua composição representam uma fonte significativa desse nutriente para sistemas aquáticos e terrestres. Uma vez formados na atmosfera, os aerossóis podem ser transportados pelos ventos, sofrer reações químicas ou retornar à superfície terrestre por processos de deposição seca e úmida. Quando depositado, o aerossol contendo espécies de nitrogênio reativo aumenta a disponibilidade de nitrogênio naquele ecossistema. Os compostos de nitrogênio reativo na forma dos íons amônio e nitrato (presentes no aerossol) podem ser prontamente aproveitados por organismos vegetais. No entanto, o excesso de disponibilidade de nitrogênio tem efeitos deletérios aos ecossistemas, pois pode levar, entre outros efeitos, à aceleração de processos de eutrofização em ambientes aquáticos e à diminuição da biodiversidade de espécies.

A eutrofização tem como ponto de partida o acúmulo de nutrientes dissolvidos na água, o que acarreta no crescimento considerável no número de algas e cianobactérias, levando a uma baixa oxigenação da água pela diminuição da passagem de luz para as plantas enraizadas que realizam fotossíntese. O problema progride e se agrava de tal modo que o nível de oxigenação do corpo d'água cessa, provocando a "morte" do ecossistema aquático. ${ }^{23}$

A diminuição da biodiversidade, por sua vez, ocorre quando excesso de nitrogênio se deposita sobre ecossistemas naturais e semi-naturais, que são adaptados a baixas taxas de fornecimento desse nutriente. A disponibilidade limitada de nitrogênio leva esses ecossistemas à uma condição de adaptação que resulta em uma baixa produtividade, mas com elevada diversidade de espécies nas comunidades vegetais. A entrada desse nutriente "adicional" advindo da deposição do aerossol contendo espécies de nitrogênio, altera as dinâmicas de crescimento das espécies de diferentes maneiras, fazendo com que haja favorecimento de umas em detrimento de outras, e perturbando o equilíbrio necessário para a manutenção da biodiversidade daquele ecossistema. ${ }^{91,92}$

Xing e colaboradores determinaram a quantidade do nitrogênio inorgânico solúvel (incluindo amônio, nitrato e nitrito) e do nitrogênio orgânico em amostras de aerossol coletados na Baía de Jiaozhou, China, entre junho de 2015 e maio de 2016. As emissões antrópicas foram as fontes mais comuns dessas formas de nitrogênio e foram transportadas por longas distâncias. Os autores alertam que o aumento nos fluxos de deposição seca de espécies de nitrogênio sobre aquele ecossistema pode ter efeitos biogeoquímicos não negligenciáveis devido ao aumento da produção primária e alteração da dinâmica dos nutrientes. ${ }^{93}$ Similarmente, Wu e colaboradores analisaram a concentração de nutrientes e calcularam os fluxos de deposição seca a partir da coleta do aerossol atmosférico na Baía de Day, China, entre 2015 e 2017. Esses autores verificaram que a deposição seca de nutrientes corresponde por aproximadamente $20 \%$ da deposição total, e sugerem que isso pode levar a um desequilíbrio na dinâmica de nutrientes na água daquela região. ${ }^{94}$

Oladosu e colaboradores coletaram água da chuva em três diferentes pontos ao longo da bacia de Lagos, Nigéria, entre maio e novembro de 2012 visando estimar a contribuição da deposição úmida no ciclo de nutrientes da lagoa. Os fluxos de deposição úmida de nitrogênio e fósforo aumentaram significativamente o aporte de nutrientes de origem antrópica sendo provavelmente responsável pela floração do gênero Hyacinths na água da lagoa durante a temporada chuvosa tardia. ${ }^{95}$

Yadav e colaboradores analisaram as concentrações de nutrientes presentes no aerossol atmosférico coletado na cidade de Visakhapatnam, localizada na costa leste da Índia, entre 2013 e 2014. Os resultados apontam que 52-89\% do nitrato proveniente do aerossol da cidade acabou se depositando nas águas costeiras. O estudo sugere que a deposição do aerossol atmosférico advindo do continente, é o responsável pelo aumento de produtividade do fitoplâncton e pela alteração na diversidade de espécies nas águas da costa leste da Índia durante o período de intervalo entre monções. ${ }^{96}$

Guo e colaboradores utilizaram um modelo para simular a emissão, formação, transporte e deposição das espécies de nitrogênio e enxofre em Louisiana, Estados Unidos, em agosto de 2011. Os autores verificaram que a deposição de nitrogênio sobre a região se dá principalmente nas formas de $\mathrm{NO}_{2}, \mathrm{HNO}_{3}, \mathrm{NH}_{3}$ e do aerossol de nitrato e, que as fontes mais significativas para esses compostos foram as emissões veiculares, industriais e agrícolas (amônia). ${ }^{97}$ Ellis e colaboradores observaram uma tendência de aumento no aporte atmosférico de amônio (198\%) e nitrato/nitrito (48\%) sobre o Lago Flathead localizado em Montana (USA), em um estudo de longo prazo, realizado entre 1985 e 2004. Os autores observaram que os íons amônio e nitrato foram as espécies majoritárias da deposição atmosférica de nitrogênio sobre o lago e, que tal deposição, pode 
ser responsável por até $6,9 \%$ da conversão de carbono em biomassa naquele ecossistema. ${ }^{98}$

Aqui no Brasil, Allen e colaboradores analisaram amostras de gases e de material particulado pelo período de um ano em uma região com emissões típicas provenientes da agroindústria (particularmente queima de biomassa) e de transporte veicular (interior de São Paulo, Sudeste do Brasil). A deposição de espécies oxidadas de N corresponderam pela deposição de quase $90 \%$ de todas as espécies nitrogenadas. $\mathrm{O} \mathrm{NO}_{2}$ foi o composto prevalente nas proximidades à áreas urbanas, enquanto que $\mathrm{o} \mathrm{HNO}_{3}$, foi a espécie majoritária depositada fora de áreas urbanas. ${ }^{99}$ Também no Brasil, Allen e colaboradores quantificaram as espécies nutrientes que contribuem para o formação do aerossol atmosférico em região rural do sudeste do Brasil. A queima de biomassa, os produtos de reações secundárias e a ressuspensão da poeira do solo responderam por $43 \%, 31 \%$ e $21 \%$ da massa de $\mathrm{MP}_{2,5}$, respectivamente. Os fluxos de deposição seca dos íons nitrato e amônio no momento do estudo foram cerca de $12 \mathrm{e}$ 3 vezes maiores, respectivamente, se comparados com os fluxos de deposição de regiões naturais remotas. ${ }^{70}$

\section{Visibilidade}

As partículas atmosféricas têm a propriedade de espalhamento e absorção da radiação. Partículas com diâmetros entre 0,1 e $1 \mu \mathrm{m}$ têm um efeito significativo de redução da visibilidade, pois seus diâmetros são comparáveis ao comprimento de onda da radiação visível. Também por conta desse efeito, a quantidade de radiação solar que chega ao solo pode ser reduzida. Quanto mais poluentes presentes na atmosfera, maior absorção e espalhamento da luz ocorrem, levando a uma redução da claridade e da cor que pode ser visualizada. Alguns tipos de partículas, em especial as que contêm sulfatos e nitratos na composição, espalham mais luz, particularmente sob condições de umidade. ${ }^{100}$

Wang e colaboradores investigaram a mudança na visibilidade e frequência de ocorrência de névoa ("haze", o termo em inglês) e o correlacionaram com a composição química do $\mathrm{MP}_{2,5}$ entre 1974 e 2017 sobre a costa leste do Mar da China. A diminuição no alcance da visibilidade média anual, era de mais de $25 \mathrm{~km}$ de distância no início dos anos 70, e passou para $18 \mathrm{~km}$ de distância nos 4 últimos anos de observação. A maior contribuição para extinção da luz foi proveniente do $\left(\mathrm{NH}_{4}\right)_{2} \mathrm{SO}_{4}$, seguido pelo $\mathrm{NH}_{4} \mathrm{NO}_{3}$ e matéria orgânica em quase todas as estações. No inverno e primavera, $\left(\mathrm{NH}_{4}\right)_{2} \mathrm{SO}_{4}$ correspondeu a $45 \%$ e $52 \%$ da extinção total da luz, respectivamente. ${ }^{101}$

Li e colaboradores conduziram o monitoramento da névoa presente sobre Pequim, China, em uma campanha de 5 dias. A concentração de $\mathrm{MP}_{2,5}$ variou de $6,30-165 \mathrm{mg} \mathrm{m}^{-3}$, com uma média de $63,8 \mathrm{mg} \mathrm{m}^{-3}$. A espécie mais abundante no material particulado foi o nitrato $(36,4 \%)$, seguido por carbono orgânico $(21,5 \%)$, amônio $(19,3 \%)$, sulfato $(18,8 \%)$ e carbono elementar $(4,10 \%)$, evidenciando o papel chave do aerossol de nitrato nos eventos de névoa. Os autores destacam que um maior controle sobre as emissões de $\mathrm{NO}_{2}$ precisa ser feito para redução dos eventos de névoa de primavera. ${ }^{102}$

Shao e colaboradores analisaram os componentes químicos de material particulado de diferentes tamanhos $\left(\mathrm{MP}_{1}, \mathrm{MP}_{2,5}\right.$ e $\left.\mathrm{MP}_{10}\right)$ coletados durante três episódios de névoa ocorridos entre 2016-2017 em Pequim, China. Os autores compararam os seus resultados com dados bem documentados de uma névoa severa ocorrida em 2013. Eles observaram que as concentrações de $\mathrm{SO}_{2}$ e $\mathrm{SO}_{4}{ }^{2-}$ e da maioria dos compostos antrópicos presentes no $\mathrm{MP}_{2,5}$ diminuíram, enquanto as concentrações de $\mathrm{NO}_{3}{ }^{-}$e $\mathrm{NH}_{4}{ }^{+}$aumentaram $77,9 \%$ e $47,3 \%$, respectivamente. A razão entre as concentrações de $\mathrm{NO}_{3}{ }^{-} / \mathrm{SO}_{4}{ }^{2-} \mathrm{em}$ $\mathrm{MP}_{1}, \mathrm{MP}_{2,5}$ e $\mathrm{MP}_{10}$ foram maiores que 1,0 , em períodos normais e de névoa. Assim, os autores concluem que para prevenir efetivamente os eventos de névoa é necessário reduzir as emissões de $\mathrm{NO}_{x}, \mathrm{NH}_{3}$, $\mathrm{SO}_{2}$ e COV simultaneamente. ${ }^{103}$

\section{CONCLUSÕES}

Os gases de nitrogênio reativo $\left(\mathrm{NH}_{3}, \mathrm{NO}, \mathrm{NO}_{2}\right.$ e $\left.\mathrm{HNO}_{3}\right)$ são compostos extremamente atuantes na química da atmosfera, com muitas de suas reações culminando na formação de aerossol atmosférico. Todos esses compostos nitrogenados desempenham um papel central nos processos físicos, químicos e bioquímicos que sustentam a vida no planeta. O desenvolvimento do Processo Haber-Bosch e a alta dependência por energia produzida através de processos de combustão foram, no século XX, e continuam a ser nesse século XXI, os responsáveis pela massiva entrada de novo nitrogênio reativo no ciclo biogeoquímico do nitrogênio. Lidar com as profundas implicações ambientais provenientes desse desequilíbrio será possivelmente um dos grandes desafios impostos ao homem e à manutenção de sua sobrevivência no planeta em um futuro próximo. Reconhecer as fontes e entender como esses compostos reagem e se transformam na atmosfera é um primeiro passo para o entendimento e gerenciamento do problema. Lacunas do conhecimento ainda permeiam o tema dos aerossóis, especialmente no que se refere aos processos de formação e crescimento do aerossol quando em dimensões nanométricas. A grande variabilidade espacial apresentada por eles, devido seu tempo de vida relativamente curto, abrem espaço para uma intensificação de estudos que investiguem seus processos de formação e papel das espécies precursoras. Somente a partir de uma ampliação e integração de resultados científicos concernentes ao tema do nitrogênio reativo e dos aerossóis atmosféricos (fontes, fluxos, transporte e sorvedouros) podem levar a um conhecimento embasado para orientar decisões de cunho normativo e para a proposição de soluções efetivas às diversas implicações mencionadas aqui.

\section{AGRADECIMENTOS}

Os autores agradecem à Fundação de Amparo à Pesquisa do Estado de São Paulo (Processo FAPESP 2016/05706-7) pelo suporte financeiro. Agradecem também ao Professor Dr. Jan Willen Erisman por conceder a permissão para adaptação e reprodução de uma de suas figuras. O Graphical Abstract foi criado utilizando vetores obtidos em Freepik.com.

\section{REFERÊNCIAS}

1. https://covid19.who.int/, acessada em Novembro 2020.

2. https://www.nytimes.com/interactive/2020/03/22/climate/coronavirususa-traffic.html, acessada em Novembro 2020.

3. https://www.weforum.org/agenda/2020/05/coronavirus-lockdown-cutsair-pollution-deaths-avoided/, acessada em Novembro 2020.

4. https://energyandcleanair.org/wp/wp-content/uploads/2020/04/CREAEurope-COVID-impacts.pdf, acessada em Novembro 2020.

5. Wu, X.; Nethery, R. C.; Sabath, M. B.; Braun, D.; Dominici, F.; medRxiv (2020), DOI: 10.1101/2020.04.05.20054502.

6. Cole, M. A.; Ozgen, C.; Strobl, E.; Air Pollution Exposure and COVID-19, IZA Institute of Labor Economics, Deutsche Post Foundation, 2020.

7. Galloway, J. N.; Cowling, E. B.; Ambio 2002, 31, 64.

8. Jin, X.; Yang, G.; Tan, C.; Zhao, C.; Sci. Rep. 2015, 5, 1.

9. Erisman, J. W.; Sutton, M. A.; Galloway, J. N.; Klimont, Z.; Winiwarter, W.; Nat. Geosci. 2008, 1, 636.

10. Galloway, J. N.; Aber, J. D.; Erisman, J. W.; Seitzinger, S. P.; Howarth, R. W.; Cowling, E. B.; Cosby, J.; BioScience 2003, 53, 341. 
11. Frost, D. C.; McDowell, C. A.; Proc. R. Soc. London, Ser. A 1956, 236 278.

12. Atkins, P. W.; Jones, L.; Princípios de Química: Questionando a vida moderna e o meio ambiente, $4^{\text {th }}$ ed., Bookman: Porto Alegre, 2006.

13. Raymond, J.; Siefert, J. L.; Staples, C. R.; Blankenship, R. E.; Mol. Biol. Evol. 2004, 21, 541 .

14. Galloway, J. N.; Dentener, F. J.; Capone, D. G.; Boyer, E. W.; Howarth, R. W.; Seitzinger, S. P.; Asner, G. P.; Cleveland, C. C.; Green, P. A.; Holland, E. A.; Karl, D. M.; Michaels, A. F.; Porter, J. H.; Townsend, A. R.; Vörösmarty, C. J.; Biogeochemistry 2004, 70, 153.

15. Erisman, J. W.; Galloway, J. N.; Seitzinger, S.; Bleeker, A.; Dise, N. B.; Petrescu, A. M. R.; Leach, A. M.; de Vries, W.; Philos. Trans. R. Soc., B (2020), DOI: 10.1098/rstb.2013.0116.

16. Standage, T. Uma história conmestível da humanidade, $1^{\text {st }}$ ed., Zahar: Rio de Janeiro, 2010.

17. Garcia, G.; Cardoso, A. A.; Santos, O. A. M; Quím. Nova 2013, 36, 1468.

18. Gu, B.; Chang, J.; Min, Y.; Ge, Y.; Zhu, Q.; Galloway, J. N.; Peng, C.; Sci. Rep. 2013, 3, 2579.

19. Vicente, E. J.; Dean, D. R.; Proc. Natl. Acad. Sci. U. S. A. 2017, 114, 3009.

20. https://news.un.org/pt/story/2019/06/1676601, acessada em Novembro 2020.

21. Erisman, J. W.; Galloway, J. N.; Dise, N. B.; Sutton, M. A.; Bleeker, A.; Grizzetti, B.; Leach, A. M.; de Vries, W.; Nitrogen: too much of a vital resource, Science Brief, WWF Netherlands, Zeist, The Netherlands, 2015.

22. Galloway, J. N.; Townsend, A. R.; Erisman, J. W.; Bekunda, M.; Cai, Z.; Freney, J. R.; Martinelli, L. A.; Seitzinger, S. P.; Sutton, M. A.; Science 2008, 320, 889 .

23. Rocha, J. C.; Rosa, A. H.; Cardoso, A. A.; Introdução à Química Ambiental, $1^{\text {st }}$ ed., Bookman: Porto Alegre, 2009.

24. https://news.un.org/pt/story/2019/07/1679631, acessada em Novembro 2020.

25. Rockström, J.; Steffen, W.; Noone, K.; Persson, A.; Chapin, F. S.; Lambin, E. F.; Lenton, T. M.; Scheffer, M.; Folke, C.; Schellnnuber, H. J.; Nykvist, B.; de Wit, C. A.; Hughes, T.; van der Leeuw, S.; Rodhe, H.; Sörlin, S.; Snyder, P. K.; Constanza, R.; Svedin, U.; Falkenmark, M.; Karlberg, L.; Corell, R. W.; Fabry, V. J.; Hansen, J.; Walker, B.; Liverman, D.; Richardson, K.; Crutzen, P.; Foley, J. A.; Nature 2009, $461,472$.

26. Suddick, E. C.; Whitney, P.; Townsend, A. R.; Davidson, E. A.; Biogeochemistry 2013, 114, 1 .

27. Climate Change 2001: The Scientific Basis; Houghton, J. T., Ding, Y., Griggs, D. J., Noguer, M., van der Linden, P. J., Dai, X., Maskell, K., Johnson, C. A., eds.; Cambridge University Press: Cambridge and New York, 2001.

28. Erisman, J. W.; BioScience 2004, 54, 286.

29. Pilegaard, K.; Philos. Trans. R. Soc., B 2013, 368, 20130126.

30. Galloway, J. N.; Leach, A. M.; Bleeker, A.; Erisman, J. W.; Philos. Trans. R. Soc., B 2013, 368, 20130120.

31. Fowler, D.; Coyle, M.; Skiba, U.; Sutton, M. A.; Cape, J. N.; Reis, S.; Sheppard, L. J.; Jenkins, A.; Grizzetti, B.; Galloway, J. N.; Vitousek, P.; Leach, A.; Bowman, A. F.; Butterbach-Bahl, K.; Dentener, F.; Stevenson, D.; Amann, M.; Voss, M.; Philos. Trans. R. Soc., B 2013, 368, 20130164.

32. Bauer, S. E.; Koch, D.; Unger, N.; Metzger, S. M.; Shindell, D. T.; Street, D. G.; Atmos. Chem. Phys. 2007, 7, 5043.

33. https://cfpub.epa.gov/ncea/iris/iris_documents/documents/ toxreviews/0422tr.pdf, acessada em Novembro 2020.

34. Félix, E. P.; Cardoso, A. A.; Quim. Nova 2004, 27, 123.

35. Krupa, S. V.; Environ. Pollut. 2003, 124, 179.

36. Xu, R.; Tian, H.; Pan, S.; Prior, S. A.; Feng, Y.; Batchelor, W. D.; Chen, J.; Yang, J.; GCB Bionergy 2019, 25, 314.
37. https://www.esrl.noaa.gov/csl/aqrsd/reports/ammonia.pdf, acessada em Novembro 2020.

38. http://www.fao.org/faostat/en/\#data/QA, acessada em Novembro 2020.

39. http://www.fao.org/3/ca6463en/ca6463en.pdf, acessada em Novembro 2020.

40. https://nepis.epa.gov/Exe/ZyPDF.cgi/91011 SPU. PDF?Dockey=91011SPU.PDF, acessada em Novembro 2020.

41. https://www.rand.org/pubs/research_reports/RR2695.html, acessada em Novembro 2020.

42. Velthof, G. L.; van Bruggen, C.; Groenestein, C. M.; de Haan, B. J.; Hogeveen, M. W.; Huijsmans, J. F. M.; Atmos. Environ. 2012, 46, 248.

43. Kulmala, M.; Vehkamäki, H.; Petäjä, T.; Dal Maso, P.; Lauri, A.; Kerminen, V. M.; Birmili, W.; McMurry, P. H.; J. Aerosol Sci. 2004, $35,143$.

44. Holmes, N. S.; Atmos. Environ. 2007, 41, 2183.

45. Kulmala, M.; Kontkanen, J.; Junninen, H.; Lehtipalo, K.; Manninen, H. E.; Nieminem, T.; Petäjä, T.; Sipilä, M.; Schobesberger, S.; Rantala, P.; Franchin, A.; Jokinen, T.; Järvinen, E.; Äijälä, M.; Kangasluoma, J.; Hakala, J.; Aalto, P. P.; Paasonen, P.; Mikkilä, J.; Vanhanen, J.; Aalto, J.; Hakola, H.; Makkonen, U.; Ruuskanen, T.; Mauldin III, R. L.; Duplissy, J.; Vehkamäki, H.; Bäck, J.; Korteilanen, A.; Riipinen, I.; Kurtèn, T.; Johnston, M. V.; Smith, J. N.; Ehn, M.; Mentel, T. F.; Lehtinen, K. E. J.; Laaksonen, A.; Kerminen, V.; Worsnop, D. R.; Science 2013, $339,943$.

46. Weber, R. J.; McMurry, P. H.; Mauldin, L.; Tanner, D. J.; Eisele, F. L.; Brechtel, F. J.; Kreidenweis, S. M.; Kok, G. L.; Schillwski, R. D.; Baumgardne, D.; J. Geophys. Res.: Atmos. 1998, 103, 16385.

47. Kirkby, J.; Curtius, J.; Almeida, J.; Dunne, E.; Duplissy, J.; Ehrhart, S.; Franchin, A.; Gagne, S.; Ickes, L.; Kürten, A.; Kupc, A.; Metzger, A.; Riccobono, F.; Rondo, L.; Schobesberger, S.; Tsakogeorgas, G.; Wimmer, D.; Amorim, A.; Bianchi, F.; Breitenlechner, M.; Daid, A.; Dommen, J.; Downard, A.; Ehn, M.; Flagan, R. C.; Haider, S.; Hansel, A.; Hauser, D.; Jud, W.; Junninen, H.; Kreissl, F.; Kvashin, A.; Laaksonen, A.; Lehtipalos, K.; Lima, J.; Lovejoy, E. R.; Makhmutov, V.; Mathot, S.; Mikkila, J.; Minginette, P.; Mogo, S.; Nieminens, T.; Onnela, A.; Pereira, P.; Petäjä, T.; Schinitzofer, R.; Seinfeld, J. H.; Sipilä, M.; Stozhkov, Y.; Stratmann, F.; Tomé, A.; Vanhanen, J.; Viisanen, Y.; Vrtala, A.; Wagner, P. E.; Walther, H.; Weingartner, E.; Wex, H.; Winkler, P. M.; Carslaw, K. S.; Worsnop, D. R.; Baltensperger, U.; Kulmala, M.; Nature 2011, 476, 429

48. Lovell-Smith, J. W.; Feistel, R.; Harvey, A. H.; Hellmuth, O.; Bell, S. A.; Heinonen, M.; Cooper, J. R.; Metrologia 2015, 53, R40.

49. Machado, C. M. D.; Cardoso, A. A.; Allen, A. G.; Environ. Sci. Technol. 2008, 42, 381

50. Caetano-Silva, L.; Allen, A. G.; Lima-Souza, M.; Cardoso, A. A.; Campos, M. L. A. M.; Nogueira, R. F. P.; J. Geophys. Res.: Atmos.2013, 118,8675 .

51. Reid, J. P.; Sayer, R. M. Chem. Soc. Rev. 2003, 32, 70.

52. Gao, Y.; Chen, S. B.; Yu, L. E.; J. Phys. Chem. A 2006, 110, 7602

53. Souza, M. L.; Allen, A. G.; Cardoso, A. A.; Atmos. Res. 2017, 183, 94.

54. Brooks, S. D., Wise, M. E., Cushing, M.; Tolbert, M. A. Geophys. Res. Lett. 2002, 29, 2.

55. Vermetten, A. W. M.; Asman, W. A. H.; Buijsman, E.; Mulder, W.; Slanina, J.; Waijers-Ijpelaan, A.; VDI Ber. 1985, 241.

56. Erisman, J. W.; Vermetten, A. W. M.; Asman, W. A. H.; Waijers-Ijpelaan, A.; Slanina, J.; Atmos. Environ. 1988, 22, 1153.

57. Vahedpour, M.; Douroudgari, H.; Afshar, S.; Asgharzade, S.; Chem. Phys. 2018, 507, 51.

58. Finlayson-Pitts, B. J.; Pitts, J. N.; Em Chemistry of the upper and lower atmosphere, $1^{\text {st }}$ ed., Academic Press: San Diego, 2000, cap. 7.

59. Crutzen, P. J.; Annu. Rev. Earth Planet. Sci. 1979, 7, 443.

60. Ludwig, J.; Meixner, F. X.; Vogel, B.; Forstner, J.; Biogeochemistry 2001, 52, 225 
61. Behrendt, T.; Veres, P. R.; Ashuri, F.; Song, G.; Flanz, M.; Mamtimin, B.; Bruse, M.; Williams, J.; Meixner, F. X.; Biogeosciences 2014, 11, 5463.

62. Oswald, R.; Behrendt, T.; Ermel, M.; Wu, D.; Su, H.; Cheng, Y.; Breuninger, C.; Moravek, A.; Mougin, E.; Delon, C.; Loubet, B.; Pommerening-Röser, A.; Sörgel, M.; Poschl, U.; Hoffmann, T.; Andreae, M. O.; Meixner, F. X.; Trebs, I.; Science 2013, 341, 1233.

63. Finlayson-Pitts, B. J.; Pitts, J. N.; Science 1997, 276, 1045.

64. Browne, E. C.; Cohen, R. C.; Atmos. Chem. Phys. 2012, 12, 11917.

65. Perring, A. E.; Pusede, S. E.; Cohen, R. C.; Chem. Rev. 2013, 113, 5848.

66. Roberts, J. M.; Atmos. Environ. 1990, 24, 243.

67. Busilacchio, M.; Di Carlo, P.; Aruffo, E.; Biancofiore, F.; Salisburgo, C. D.; Giammaria, F.; Bauguitte, S.; Lee, J.; Moller, S.; Hopkins, J.; Punjabi, S.; Andrews, S.; Lewis, A. C.; Parrington, M.; Palmer, P. I.; Hyer, E.; Wolfe, G. M.; Atmos. Chem. Phys. 2016, 16, 3485.

68. Day, D. A.; Wooldridge, P. J.; Dillon, M. B.; Thornton, J. A.; Cohen, R. C.; J. Geophys. Res.: Atmos. 2002, 107, 4046.

69. Lelieveld, J.; Evans, J. S.; Fnais, M.; Giannadaki, D.; Pozzer, A.; Nature 2015, 525, 367.

70. Allen, A. G.; Cardoso, A. A.; Wiatr, A. G.; Machado, C. M. D.; Paterlini, W. C.; Baker, J.; J. Braz. Chem. Soc. 2010, 21, 87.

71. Freitas, A. M.; Solci, M. C.; Quim. Nova 2009, 32, 1750.

72. https://cetesb.sp.gov.br/ar/padroes-de-qualidade-do-ar/, acessada em Novembro 2020.

73. Giannadaki, D.; Giannakis, E.; Pozzer, A.; Lelieveld, J.; Sci. Total Environ. 2018, 622-623, 1304.

74. Pozzer, A.; Tsimpidi, A. P.; Karydis, V. A.; Meij, A.; Lelieveld, J.; Atmos. Chem. Phys. 2017, 17, 12813.

75. Julin, J.; Murphy, B. N.; Patoulias, D.; Fountoukis, C.; Olenius, T.; Pandis, S. N.; Riipinen, I.; Environ. Sci. Technol. 2018, 52, 692.

76. Lu, M.; Lin, B.; Inoue, K.; Lei, Z.; Zhang, Z.; Tsunemi, K.; Front. Environ. Sci. Eng. 2018, 12, 13.

77. Thakrar, S. K.; Goodkind, A. L.; Tessum, C. W.; Marshall, J. D.; Hill, J. D.; Biomass Bioenergy 2018, 114, 73.

78. Hristov, A. N.; J. Dairy Sci. 2011, 94, 3130.

79. Otmani, A.; Benchrif, A.; Tahri, M.; Bounakhla, M.; Chakir, E. M.; Bouch, M. E.; Krombi, M.; Sci. Total Environ. 2020, 735, 139541.

80. Bao, R.; Zhang, A.; Sci. Total Environ. 2020, 731, 139052.

81. Nakada, L. Y. K.; Urban, R. C.; Sci. Total Environ. 2020, 730, 139087.

82. Krecl, P.; Targino, A. C.; Oukawa, G. Y.; Cassino Junior, R. P.; Environ. Pollut. 2020, 265, 114883.

83. Ogen, Y.; Sci. Total Environ. 2020, 726, 138605.

84. Forster, P.; Ramaswamy, V.; Artaxo, P.; Berntsen, T.; Betts, R.; Fahey, D. W.; Haywood, J.; Lean, J.; Lowe, D. C.; Myhre, G.; Nganga, J.; Prinn, R.; Raga, G.; Schulz, M.; van Dorland, R. Em Climate Change 2007: The Physical Science Basis. Contribution of Working Group I to the Fourth Assessment Report of the Intergovernmental Panel on Climate Change; Solomon, S., Qin, D., Manning, M., Chen, Z., Marquis, M., Averyt, K. B., Tignor, M., Miller, H. L., eds.; Cambridge University Press: Cambridge, 2007, cap. 2.

85. Ramaswamy, V.; Boucher, O.; Haigh, J.; Hauglustaine, D.; Haywood, J.; Myhre, G.; Nakajima, T.; Shi, G. Y.; Solomon, S. Em IPCC, 2001:
Climate Change 2001: The Scientific Basis. Contribution of Working Group I to the Third Assessment Report of the Intergovernmental Panel on Climate Change; Joos, F., Srinivasan, J., eds.; Cambridge University Press: Cambridge, 2001, cap. 6.

86. Myhre, G.; Shindell, D.; Breon, F. M.; Collins, W.; Fuglestvedt, J.; Huang, J.; Koch, D.; Lamarque, J. F.; Lee, D.; Mendoza, B.; Nakajima, T.; Robock, A.; Stephens, G.; Takemura, T.; Zhang, H. Em Climate Change 2013: The Physical Science Basis. Contribution of Working Group I to the Fifth Assessment Report of the Intergovernmental Panel on Climate Change; Sotcker, T. F., Qin, D., Plattner, G. K., Tignr, M., Allen, S. K., Boschung, J., Nauels, A., Xia, Y., Bex, V., Midgley, P. M., eds.; Cambridge University Press: Cambridge, 2013, cap. 8.

87. Ramaswamy, V.; Collins, W.; Haywood, J.; Lean, J.; Maholwald, N.; Myhre, G.; Naik, V.; Shine, K. P.; Soden, B.; Stenchikov, G.; Storelvmo, T.; Meteorol. Monogr. (2019), DOI: 10.1175/ AMSMONOGRAPHS-D-19-0001.1.

88. Ramanathan, V.; Crutzen, P. J.; Kiehl, J. T.; Rosenfeld, D.; Science 2001, 294, 2119.

89. Rosenfeld, D.; Science 2000, 287, 1793.

90. Maahn, M.; de Boer, G.; Creamean, J. M.; Feingold, G.; McFarquhar, G. M.; Wu, W.; Mei, F.; Atmos. Chem. Phys. 2017, 17, 14709.

91. Phoenix, G. K.; Hicks, W. K.; Cinderby, S.; Kuylenstierna, J. C. I.; Stock, W. D.; Dentener, F. J.; Giller, K. E.; Austin, A. T.; Lefroy, R. D. B.; Gimeno, B. S.; Ashmore, M. R.; Ineson, P.; GCB Bioenergy 2006, 12,470 .

92. Bobbink, R.; Hicks, K.; Galloway, J. N.; Spranger, T.; Alkemade, R.; Ashmore, M.; Bustamente, M.; Cinderby, S.; Davidson, E.; Dentener, F.; Emmet, B.; Erisman, J. W.; Fenn, M.; Gilliam, F.; Nordin, A.; Pardo, L.; de Vries, W.; Ecol. Appl. 2010, 20, 30.

93. Xing, J.; Song, J.; Yuan, H.; Wang, Q.; Li, X.; Li, N.; Duan, L.; Qu, B.; Atmos. Res. 2018, 207, 90.

94. Wu, Y.; Zhang, J.; Liu, S.; Jiang, Z.; Huang, X.; Mar. Pollut. Bull. 2018, 128,106

95. Oladosu, N. O.; Abayomi, A. A.; Olayinka, K. O.; Alo, B. I.; Environ. Sci. Pollut. Res. 2017, 24, 8645.

96. Yadav, K.; Sarma, V. V. S. S.; Rao, D. B.; Kumar, M. D.; Mar. Chem. 2016, 187, 25.

97. Guo, H.; Han, F.; Wang, Z.; Pardue, J.; Zhang, H.; Sci. Total Environ. 2018, 636, 124 .

98. Ellis, B. K.; Craft, J. A.; Stanford, J. A.; PeerJ (2015), DOI: 10.7717/ peerj. 841

99. Allen, A. G.; Machado, C. M. D.; Cardoso, A. A.; Environ. Pollut. 2011, $159,1190$.

100. https://www.epa.gov/visibility/basic-information-about-visibility, acessada em Novembro 2020.

101. Wang, B.; Chen, Y.; Zhou, S.; Li, H.; Wang, F.; Yang, T.; Sci. Total Environ. 2019, 649, 652.

102. Li, H.; Duan, F.; Ma, Y.; He, K.; Zhu, L.; Ma, T.; Ye, S.; Yang, S.; Huang, T.; Kimoto, T.; Environ. Pollut. 2018, 242, 544.

103. Shao, P.; Tian, H.; Sun, Y.; Liu, H.; Wu, B.; Liu, S.; Liu, X.; Wu, Y.; Liang, W.; Wang, Y.; Gao, J.; Xue, Y.; Bai, X.; Liu, W.; Lin, S.; Hu, G.; Atmos. Environ. 2018, 189, 133. 